\title{
DIRDOP: a directivity approach to determining the seismic rupture velocity vector
}

\author{
Bento Caldeira • Mourad Bezzeghoud • \\ José F. Borges
}

Received: 7 July 2008 / Accepted: 18 November 2009 / Published online: 17 December 2009

(C) The Author(s) 2009. This article is published with open access at Springerlink.com

\begin{abstract}
Directivity effects are a characteristic of seismic source finiteness and are a consequence of the rupture spread in preferential directions. These effects are manifested through seismic spectral deviations as a function of the observation location. The directivity by Doppler effect method permits estimation of the directions and rupture velocities, beginning from the duration of common pulses, which are identified in waveforms or relative source time functions. The general model of directivity that supports the method presented here is a Doppler analysis based on a kinematic source model of rupture (Haskell, Bull Seismol Soc Am 54:1811-1841, 1964) and a structural medium with spherical symmetry. To evaluate its performance, we subjected the method to a series of tests with synthetic data obtained from ten typical seismic ruptures. The experimental conditions studied correspond with scenarios of simple and complex, unilaterally and bilaterally extended ruptures with different mechanisms and datasets with different levels of azimuthal coverage. The obtained results generally agree with the expected values. We also present four real case studies, applying the
\end{abstract}

B. Caldeira $(\varangle) \cdot$ M. Bezzeghoud · J. F. Borges

Centro de Geofísica de Évora (CGE)

e Departamento de Física,

Universidade de Évora, Évora, Portugal

e-mail: bafcc@uevora.pt method to the following earthquakes: Arequipa, Peru $\left(M_{\mathrm{w}}=8.4\right.$, June 23, 2001); Denali, AK, USA $\left(M_{\mathrm{w}}=7.8\right.$; November 3, 2002); ZemmouriBoumerdes, Algeria $\left(M_{\mathrm{w}}=6.8\right.$, May 21, 2003); and Sumatra, Indonesia $\left(M_{\mathrm{w}}=9.3\right.$, December 26, 2004). The results obtained from the dataset of the four earthquakes agreed, in general, with the values presented by other authors using different methods and data.

Keywords Directivity - Doppler effect •

Seismic source $\cdot$ Rupture parameters Inversion

\section{Introduction}

The radiation that issues from an extended seismic source when a rupture spreads in preferential directions has characteristics that distinguish it from the radiation emitted by a point source (Benioff 1955). These distinctive characteristics, which are known as directivity (Ben-Menahem 1961), are manifested by an increase in the frequency and amplitude of seismic waves when the rupture occurs in the direction of the seismic station and a decrease in the frequency and amplitude if it occurs in the opposite direction. Moreover, these effects are not present when the rupture's direction is perpendicular to the propagation direction. Evidence of this behavior is found in a multiplicity of seismic observations (Fig. 1), including the 
Fig. 1 Effects of rupture directivity: a common pulse duration at different azimuths from the rupture, b corner frequency variation on spectra diagrams of body wave displacement, c pulse duration variation observed in relative source time functions, and d symmetric change of the radiation pattern with maximum amplitude related to the direction of the rupture a

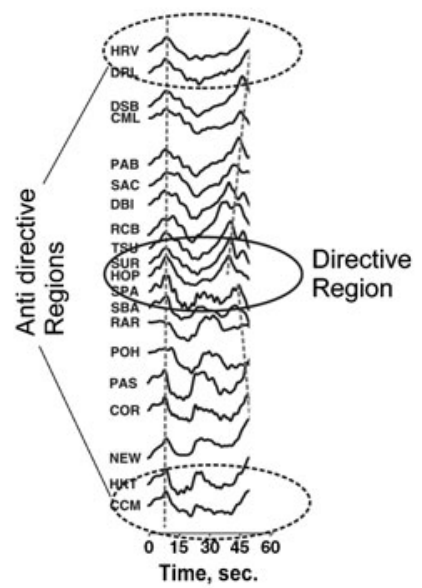

C

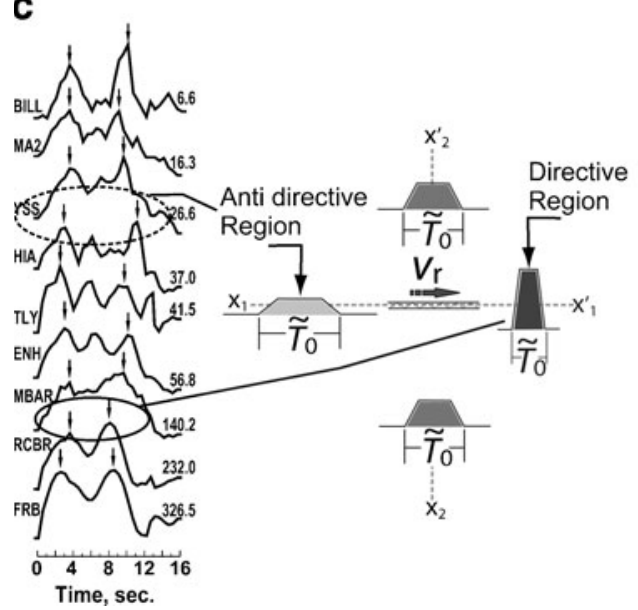

b

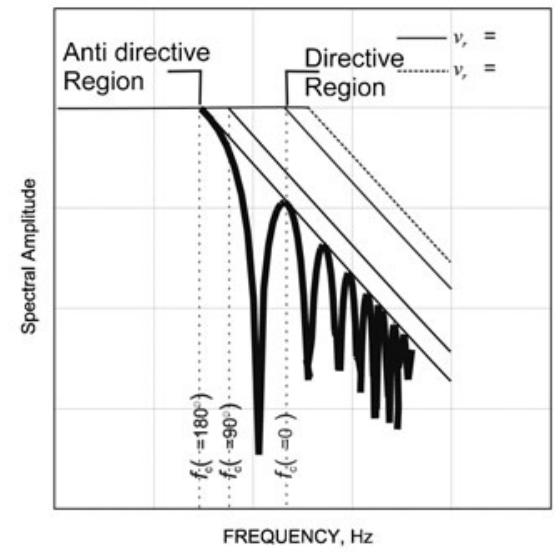

d

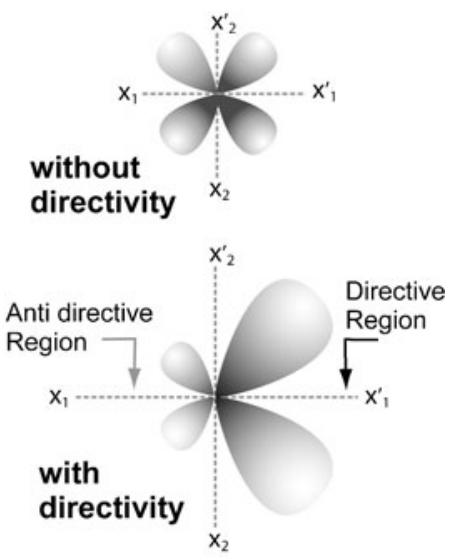

following: (a) a variation of pulse duration observed in waveforms at stations with differing azimuths (e.g., Fukao 1972; Tibi et al. 1999; Caldeira et al. 2004), (b) variations of corner frequencies observed in the amplitude spectra (e.g., Tumarkin and Archuleta 1994; Hoshiba 2003), (c) pulse duration variations observed in relative source time functions (RSTF; e.g., Ihmlé 1998; Baumont et al. 2002; Kraeva 2004), and (d) symmetric changes of the radiation pattern in which the maximum amplitude is related to the direction of the rupture (e.g., Benioff 1955; Ben-Menahem and Singh 1981; Kasahara 1981).

The term directivity that is associated with spectral deviations caused by finite moving sources was first used by Ben-Menahem (1961), who quantified it with the directivity function $D_{\theta}(\omega)$. This function is defined as the ratio of the spectral displacements from two places that are diametrically opposite from the focus. Considering a kinematic model of rupture propagation, as in Haskell (1964), and a homogeneous and isotropic medium, the zeros of the directivity function occur at frequencies

$\omega_{n}(D=0)=\frac{2 n \pi}{\tilde{T}_{0}(\theta)}, \quad(n=1,2 \ldots)$,

where $\tilde{T}_{0}(\theta)$ is the apparent source rupture time observed at a station whose relation to the 
epicenter defines an angle $\theta$ with the direction of the rupture. $\tilde{T}_{0}(\theta)$ is written in the form

$\tilde{T}_{0}(\theta)=\frac{L}{v_{\mathrm{r}}}-\frac{L}{c} \cos \theta$,

where $L$ is the rupture length, $v_{\mathrm{r}}$ the rupture velocity, and $c$ the phase velocity of the wave (P or $\mathrm{S})$.

The apparent rupture time $\tilde{T}_{0}(\theta)$ is the result of two terms: $L / v_{\mathrm{r}}$, which represents the real source duration, i.e., the rupture time when measured in its own referential, and $-(L / c) \cos \theta$, which expresses the delay relative to the real rupture time. This term is a function of the observation direction.

These directivity effects are believed by some authors to be equivalent to the Doppler effect (e.g., Ben-Menahem and Singh 1981; Douglas et al. 1988; Velasco et al. 2004); however, this interpretation is not unanimously accepted. For example, Aki and Richards (1980) and Bullen and Bolt (1985) found the two effects to be different, although they do recognize analogies between them. Aki and Richards (1980), for example, pointed out that the amplitude variations caused by destructive interference between the waves originating from different positions on the fault are a distinctive feature of seismic directivity. According to them, this feature clearly shows the difference between the two effects. The Doppler effect, in its classical formulation, is in fact limited to a single oscillation. Douglas et al. (1988) compare the theoretical models of the Doppler effect and seismic directivity and show that, in both cases, the equations are identical although they are ascertained differently. They concluded that it is appropriate to associate Doppler's name with the effect of the variation in pulse shape due to a moving seismic source. The polychromatic nature of the source does not fundamentally invalidate the applicability of the Doppler analysis. Some similar problems occur in other scientific areas, involving multifrequency oscillators that are also known as Doppler (e.g., Loupas and Gill 1994; Grach et al. 1997; Russell and Brucher 2002; Rao et al. 2009).

Although seismic directivity is recognized unanimously as being characteristic of extended sources and as a function of some important source parameters, such as length, rupture direction, rupture velocity, and rupture time, it is not a widely studied subject. Its use in determining source parameters from seismic records has been developed in two ways:

(a) The first method, based on the directivity function of Ben-Menahem (1961) (e.g., BenMenahem and Singh 1981; Udias 1971; Pro 2002; Pro et al. 2007), consists of finding the length of the source and the rupture velocity that produces a good visual fit between the synthetic and observed diagrams of the directivity function calculated using surface waves. This method requires knowledge of the rupture azimuth and pairs of records acquired at equidistant and diametrically opposite locations from the source. These requirements are always difficult to satisfy. Pro (2002), on the other hand, developed a method that allows pairs of data to be used although they are not from exactly opposite locations. She also used a method based on the first minima of Eq. 1 to decide which planes of the focal mechanism correspond to the rupture.

(b) The second approach uses the apparent duration of the rupture gathered from seismic waveforms or from the apparent source time functions, which are both azimuthally distributed. Equation 2 is then applied to estimate the parameters of source finiteness (e.g., Fukao 1972; Boore and Joyner 1978; Cipar 1979; Beck et al. 1995; Ihmlé 1998; Tibi et al. 1999; Kraeva 2004)

In this study, we use a similar scheme to determine the direction and rupture velocity and the corresponding errors. The directivity by Doppler effect (DIRDOP) program uses time delays between common pulses selected in broadband seismic body waves with an azimuthal distribution around the epicenter; it calculates the source parameters through a subsequent Doppler analysis.

To evaluate the program, we applied it to a set of synthetic data from typical scenarios of seismic ruptures. Finally, to test the program on a real situation, we applied it to four earthquakes: Arequipa, Peru $\left(M_{\mathrm{w}}=8.4\right.$, June 23, 2001); Denali, AK, USA $\left(M_{\mathrm{w}}=7.8\right.$, November 3, 2002); 
Zemmouri-Boumerdes, Algeria $\left(M_{\mathrm{w}}=6.8\right.$, May $21,2003)$; and Sumatra, Indonesia $\left(M_{\mathrm{w}}=9.3\right.$, December 26, 2004).

\section{Theory}

The rupture process of an extended seismic source can be viewed as a sequence of shocks due to rapid slips, which are produced along certain fault paths. Each shock causes vibrations that spread in all directions of the Earth's interior following the laws of seismic wave propagation theory.

According to this model, the seismic record at any point on the earth's surface contains a signature of the rupture process that originated the recorded waveform. It is possible, by comparing several readings of waveforms azimuthally distributed from the source, to analyze the Doppler effect, so as to determine the direction and velocity of the rupture. In general, the physical phenomenon known as the Doppler effect occurs whenever a wave's source moves relative to an observer. It is revealed by variations in the frequencies recorded by observers distributed at different points in relation to the source.

When the source moves with a rupture velocity $v$ and emits wave pulses that propagate in a homogeneous and isotropic medium with a constant phase velocity $c$, the Doppler effect can be mathematically expressed (French 1974) as

$$
\Delta \tau=\Delta \tau_{0}\left(1-\frac{v \cos \theta}{c}\right)
$$

where $\Delta \tau_{0}$ is the time delay between two pulses measured in the source referential, $\Delta \tau$ is the equivalent time delay measured at a fixed position that forms an angle $\theta$ with the direction of movement from the source, and $c$ is the phase velocity of the wave in the medium. Equation 3 shows that the measurement performed by an external observer depends on the source component velocity in the incidence direction of the wave, $v \cos \theta$. Any application of this effect should take into account this rule, i.e., that the second term of Eq. 3 is the ratio between the components of source velocity in the wave incidence direction and its phase velocity. After the necessary modifications for the propagation of seismic rays in a spherically layered medium, the following is the equivalent equation that relates the measurement of the time delay between two shocks that occur at the source with an interval $\Delta \tau_{0}$ spread with a constant velocity $v_{\mathrm{r}}$, with the corresponding time delay $\Delta \tau_{j}$ measured at station $j$ :

$\Delta \tau_{j}(\theta, i)=\Delta \tau_{0}\left(1-\frac{v_{\mathrm{rH}} \sin i_{j} \cos \theta_{j}}{c}\right)$.

Here, $v_{\mathrm{rH}}$ is the horizontal component of the rupture velocity and $i_{j}$ is the incidence angle at the $j$-th observation location. Inserting the slowness parameter $p$ into Eq. 4 , the equation becomes

$\Delta \tau_{j}(\theta, p)=\Delta \tau_{0}\left(1-\frac{p_{j}}{R_{0}} v_{\mathrm{rH}} \cos \theta_{j}\right)$,

where $R_{0}$ is the Earth's radius. According to Eq. 5 , $\Delta \tau_{j}$ depends on two variables: the distance from the source $\left(p_{j} / R_{0}\right)$ and the angle between the rupture direction and the station position $\left(\theta_{j}\right)$. The spatial distribution of $\Delta \tau_{j}$ is schematically represented in Fig. 2. According to Eq. 5, $\Delta \tau_{j}$

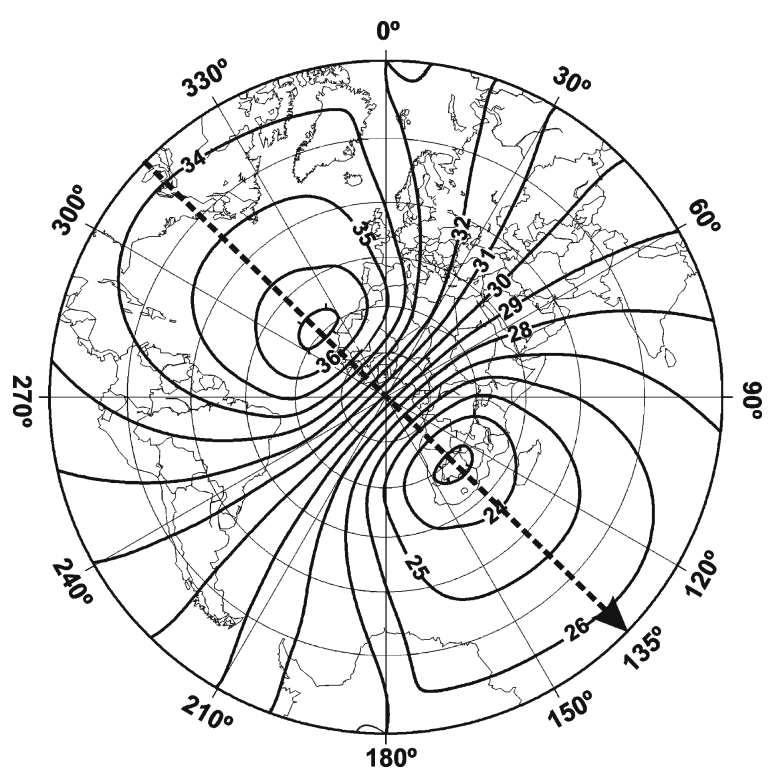

Fig. 2 Theoretical spatial distribution (isolines) of common pulses (time delays) measured on seismograms obtained from an extended seismic source located at latitude $=0^{\circ}$, longitude $=0^{\circ}$. The rupture propagates with a constant velocity, $v_{\mathrm{r}}=3.0 \mathrm{~km} / \mathrm{s}$, toward N135E. In the source, we considered a 30-s time pulse, which is the value read from seismograms in directions perpendicular to the rupture 
for equidistant positions from the focus is minimal for $\theta=0^{\circ}$, that is, in positions aligned with the direction of rupture progression, and has the value $\Delta \tau_{0}$ at positions perpendicular to the rupture direction. Thus, by examining the azimuthal distribution of apparent time delays, $\Delta \tau_{j}(\theta, p)$, it is possible to evaluate the direction of the rupture.

Calculating the rupture velocity requires careful analysis. In reality, the data frequently come from restricted and poorly distributed observation points in azimuth, as well as distance. Because of this, diagrams constructed with real data, such as Fig. 2, do not explicitly define the rupture direction. For the same reason, estimates of $v_{\mathrm{rH}}$ calculated using these data can also be imprecise. This difficulty can be overcome by normalizing measures to a standard value $p_{0}$ of slowness. The normalization transforms the equation of two variables, Eq. 5, into one involving only one variable,

$\Delta \tau_{j}^{*}(\theta)=\Delta \tau_{0}\left[1-v_{\mathrm{rH}}\left(\frac{p_{0}}{R_{0}}\right) \cos \theta_{j}\right]$,

where $\Delta \tau_{j}^{*}$ are the normalized time delays. Figure 3 represents the time delays normalized to a distance of $30^{\circ}, \Delta \tau_{j}^{*}$, as a function of the azimuth of the observation locations $\theta$.

According to Eq. 6, the minimum of $\Delta \tau^{*}, \Delta \tau_{\min }^{*}$, is measured at an observation location that defines the direction of $v_{\mathrm{rH}}$, an angle $\theta_{j}=0$. On the other hand, at the points orthogonal to that direction $\left(\theta_{j}=90^{\circ}\right), \Delta \tau^{*}=\Delta \tau_{0}$. Finally, with these two pa- rameters, $\Delta \tau_{\min }^{*}$ and $\Delta \tau_{0}$, obtained from the curves (see Fig. 3), we can calculate $v_{\mathrm{rH}}$ :

$v_{\mathrm{rH}}=\frac{1-\left(\Delta \tau_{\min }^{*} / \Delta \tau_{0}\right)}{p_{0} / R_{0}}$

The normalization procedure consists of calculating the correction parameter $\chi_{j}$, which provides the measurements at the standard distance for each observation point, using

$\Delta \tau_{j}^{*}(\theta)=\Delta \tau_{j}(\theta, p) \chi_{j}$,

where the normalization parameter is given by

$\chi_{j}=\frac{1-v_{\mathrm{rH}}\left(\frac{p_{0}}{R_{0}}\right) \cos \theta_{j}}{1-v_{\mathrm{rH}}\left(\frac{p_{j}}{R_{0}}\right) \cos \theta_{j}}$.

The calculation of $v_{\mathrm{rH}}$ from Eqs. 7, 8, and 9 is a nonlinear inverse problem that we can solve numerically using an iterative nonlinear leastsquares method (Menke 1984). Because the distribution of the data is assumed to be Gaussian, the errors of velocity and azimuth of rupture are calculated from the covariance matrix of inverted parameters.

The method, as it was used, calculates the horizontal component of the rupture velocity $v_{\mathrm{rH}}$; the rupture velocity $v_{\mathrm{r}}$, on the other hand, can be estimated if the geometric fault parameters (strike $=$ $\phi$ and $\operatorname{dip}=\delta$ ) are known. For the geometry shown in Fig. 4, the rupture velocity is given by

$v_{\mathrm{r}}=\frac{v_{\mathrm{rH}}}{\cos \delta} \sqrt{\cos ^{2} \psi \cos ^{2} \delta+\sin ^{2} \psi}$
Fig. 3 Azimuthal distribution of the pulses represented in Fig. 2 to a normalized distance of $30^{\circ}$, which corresponds to $p_{0} / R_{0}=0.08 \mathrm{~s} / \mathrm{km}$. The minimum of the curve occurs in the direction of the rupture and the maximum in the opposite direction

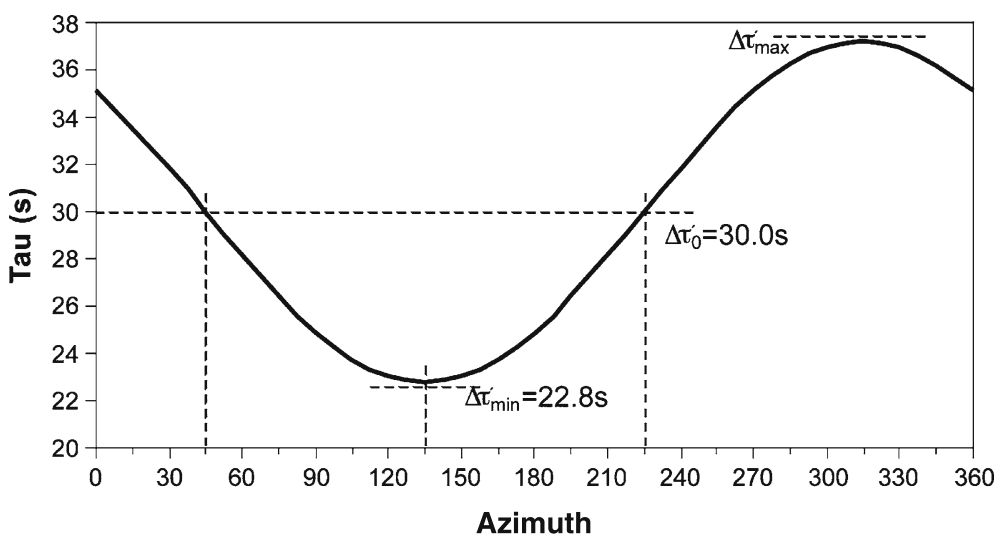


Fig. 4 Description of the geometric parameters used to represent the fault orientation with (top) and without (bottom) projection on the surface

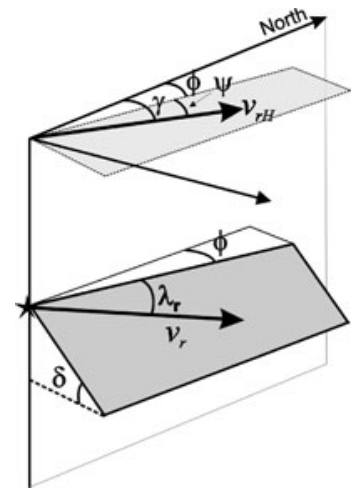

and the rupture direction on the fault plane by

$\lambda_{\mathrm{r}}=\arctan \left(\frac{\tan \psi}{\cos \delta}\right)$,

where $\psi=\gamma-\phi$.
The procedure described above establishes the DIRDOP approach that allows for calculation of the rupture direction and velocity for extended seismic sources using the common pulses identified on seismograms of stations distributed around the source. Consider the special case of a unilateral rupture with constant velocity, as described in the kinematic Haskell model. If, in each seismogram, a delay interval, $\Delta \tau_{j}$, is selected that corresponds to the difference between the initial and final pulse times of the rupture, $\Delta \tau_{j}(\theta, p)=$ $\tilde{T}_{0}(\theta, p)$, the apparent rupture time. In this case, $\Delta \tau_{0}=L / \nu_{\mathrm{r}}$, where $L$ is the rupture length. Under these conditions, the application of DIRDOP to this particular case (Eq. 5) becomes

$$
\tilde{T}_{0}(\theta, p)=\frac{L}{v_{\mathrm{r}}}-\frac{p L}{R_{0}} \cos \theta .
$$

Fig. 5 Source time functions (STF) used to generate the synthetic waveforms of the extended ruptures. The STF is the sum of narrow triangular functions (rise time of $1 \mathrm{~s}$ ) with different amplitudes at regular time intervals. The highest triangles produce stronger visual marks on the synthetic

seismograms, making the corresponding pulses more easily identifiable. In a, the STF used is associated with unilateral ruptures (scenarios $\mathrm{S} 1$, S2, S3, S4, and S5); in b, the STF used is related to a bilateral rupture (scenario S6); c STF similar to the Arequipa (Peru), June 23, 2001 earthquake, used to generate the complex unilateral ruptures $\mathrm{C} 1$, $\mathrm{C} 3$, and $\mathrm{C} 4$; and $\mathbf{d} \mathrm{STF}$ used to generate the bilateral rupture $\mathrm{C} 2$
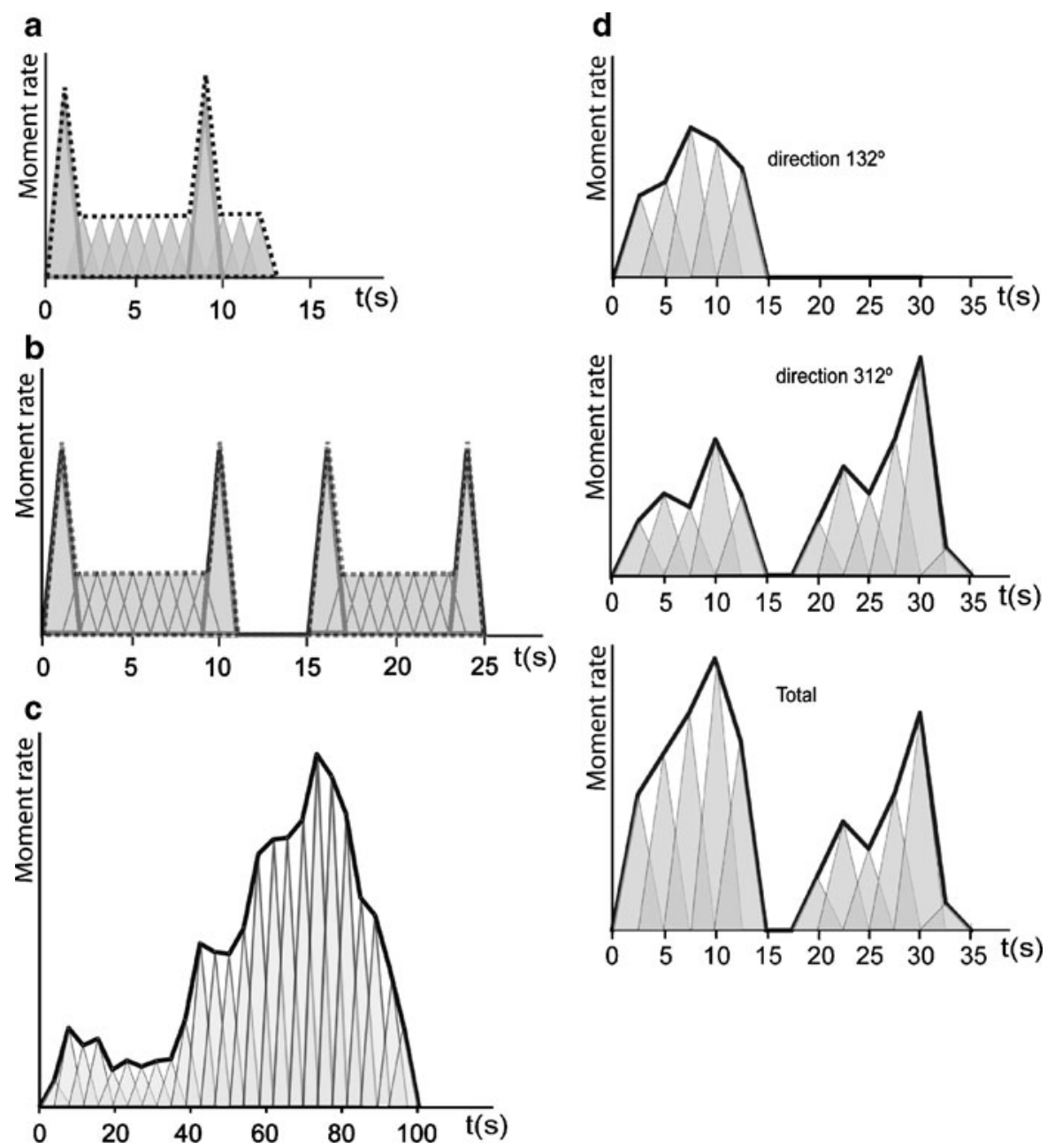
Equation 12 defines the apparent source time rupture as a function of the observation point. An identical equation can be deduced by integrating the Haskell (1964) rupture model applied to a layered spherical structure model (Fukao 1972; Caldeira 2004).

\section{Evaluation of the method}

To evaluate this methodology, we applied it to a set of typical synthetic scenarios of seismic ruptures. This kind of evaluation with synthetic data is extremely important because it represents the only way to analyze the performance of the methods because the expected results are known (Beresnev 2003).

\subsection{Synthetic data}

The data used were obtained from synthetic seismograms generated by Borges' (2003) KIKDIREC program. This program is based on the seismic source model of Kikuchi and Kanamori (1991), which synthesizes the displacement, $u_{j}$, produced at any point on the Earth's surface due to an extended seismic rupture in its interior. The rupture is defined by a succession of point sources distributed on a rectangular fault characterized by the parameters $\varphi$ (strike) and $\delta$ (dip; Fig. 4). Each subevent is characterized by a triangular source time function (STF) with rise time $\tau$ and a slip vector defined by an angle $\lambda$ (rake). The rupture velocity is defined using the position and occurrence time of each point source, which in turn are defined by the three parameters $\Delta D$, $\Delta t$, and $\lambda_{\mathrm{r}}$, which represent the distance between subevents, the time interval between subevents, and the rupture direction on the fault, respectively. The complete STFs (Fig. 5) are defined by a sequence of partially overlapping triangular functions. The structure model used to calculate the Green functions was the ISASP91 model of Kennett and Engdahl (1991).

Ten scenarios (defined in Table 1) were tested. The first six, with the denomination $\mathrm{S}$ (from 1 to 6), correspond to a very simple STFs (Fig. 5a, b); the last four, with the denomination $\mathrm{C}$ (from 1 to 4), correspond to STSs representative of the complexity observed in real earthquakes. For scenarios C1, C3, and C4, the 2001 Arequipa (Peru) STF (Fig. 5c) was used (Caldeira 2004). In scenario $\mathrm{C} 2$, which corresponds to a bilateral rupture, the STF represented in Fig. 5d was used. Except for scenarios $\mathrm{S} 6$ and $\mathrm{C} 2$, which represent bilateral ruptures, all of the scenarios are unilateral. The ruptures defined in scenarios $\mathrm{S} 1, \mathrm{~S} 2, \mathrm{~S} 3, \mathrm{~S} 4 \mathrm{C} 1$,

Table 1 Rupture parameters used to calculate the synthetic seismograms

\begin{tabular}{|c|c|c|c|c|c|c|c|c|}
\hline \multirow[t]{3}{*}{ Scenario } & \multirow{2}{*}{\multicolumn{2}{|c|}{ Fault geometry }} & \multicolumn{3}{|c|}{ Subevents } & \multicolumn{2}{|c|}{ Rupture definition } & \multirow{3}{*}{$\begin{array}{l}\text { Observation } \\
\text { distance } \\
\Delta(\operatorname{deg})\end{array}$} \\
\hline & & & \multirow{2}{*}{$\frac{\text { Rake }}{\lambda(\mathrm{deg})}$} & \multirow{2}{*}{$\begin{array}{l}\text { Distance } \\
\Delta D(\mathrm{~km}) \\
\end{array}$} & \multirow{2}{*}{$\begin{array}{l}\text { Time separation } \\
\Delta t(\mathrm{~s})\end{array}$} & \multirow{2}{*}{$\begin{array}{l}\text { Direction } \\
\lambda_{\mathrm{r}}(\mathrm{deg})\end{array}$} & \multirow{2}{*}{$\frac{\text { Velocity }}{v_{\mathrm{r}}(\mathrm{km} / \mathrm{s})}$} & \\
\hline & $\phi(\operatorname{deg})$ & $\delta(\operatorname{deg})$ & & & & & & \\
\hline $\mathrm{S} 1 \mathrm{U}$ & 67.5 & 45.0 & 80.0 & 2.6 & 1.0 & 0.0 & 2.60 & 30 \\
\hline $\mathrm{S} 2 \mathrm{U}$ & 7.5 & 45.0 & -80.0 & 2.6 & 1.0 & 0.0 & 2.60 & 30 \\
\hline S3 U & 7.5 & 90.0 & 0.0 & 2.5 & 1.0 & 0.0 & 2.50 & 30 \\
\hline S4 U & 67.5 & 45.0 & 80.0 & 2.6 & 1.0 & 0.0 & 2.60 & Vary \\
\hline S5 U & 52.5 & 45.0 & 80.0 & 2.8 & 1.0 & -30.0 & & \\
\hline \multirow[t]{2}{*}{ S6 B } & 67.5 & 45.0 & 80.0 & 3.5 & 1.0 & $0.0^{\mathrm{a}}$ & 2.80 & Vary \\
\hline & & & & & & $180.0^{\mathrm{b}}$ & 3.55 & 30 \\
\hline C1 U & 312.0 & 13.0 & 60.0 & 11.2 & 4.0 & $180.0^{\mathrm{c}}$ & 2.8 & 35 \\
\hline $\mathrm{C} 2 \mathrm{~B} / \mathrm{U}$ & 312.0 & 13.0 & 60.0 & 8.5 & 2.5 & $0^{\mathrm{d}}$ & 3.4 & 35 \\
\hline C3 U & 312.0 & 13.0 & 60.0 & 10.8 & 4.0 & 180.0 & 2.7 & Vary \\
\hline $\mathrm{C} 4 \mathrm{U}$ & 312.0 & 13.0 & 60.0 & 5.08 & 5.08 & 180.0 & 1.0 & Vary \\
\hline
\end{tabular}

$U$ unilateral, $B$ bilateral

${ }^{\text {a}}$ First part of the rupture

${ }^{\mathrm{b}}$ Second part of rupture

${ }^{\mathrm{c}}$ Bilateral in the first $15 \mathrm{~s}$, with simultaneously $0^{\circ}$ and $180^{\circ}$

${ }^{\mathrm{d}}$ Unilateral in strike direction 
$\mathrm{C} 2, \mathrm{C} 3$, and $\mathrm{C} 4$ correspond to horizontal ruptures on a fault plane with different source mechanisms or rupture velocity (Table 1); scenario S5 corresponds to an oblique rupture $\left(\lambda_{\mathrm{r}}=30^{\circ}\right)$ and, therefore, contains a vertical component. In the simple bilateral scenario S6, the rupture spreads in the azimuth direction in the first $10 \mathrm{~s}$ and subsequently moves in the reverse direction; in both cases, it has a velocity of $3.55 \mathrm{~km} / \mathrm{s}$. However, in the complex bilateral scenario, $\mathrm{C} 2$, the rupture was defined with more realistic behavior: In the first $15 \mathrm{~s}$, it spreads simultaneously in two opposite directions $\left(132^{\circ}\right.$ and $\left.312^{\circ}\right)$, with each controlled by a temporal function, which is represented in
Fig. 5d. In the last part of the rupture (between 17.5 and $35 \mathrm{~s}$ ), the spread continues only in the $312^{\circ}$ direction (Table 1 ).

For each scenario, $\mathrm{P}$ vertical waveforms were produced at a set of observation points distributed around the epicenter. In scenarios S1, S2, S3, S6, $\mathrm{C} 1$, and $\mathrm{C} 2$, all of the synthetic seismograms were computed at the same epicentral distances and uniformly distributed (with an interval of $15^{\circ}$ ) around the source. In scenarios $\mathrm{S} 4, \mathrm{~S} 5, \mathrm{C} 3$, and C4, variable distances were considered: For $\mathrm{S} 4$ and $\mathrm{S} 5$, distances between $30^{\circ}$ and $90^{\circ}$ were used but were uniformly distributed around the source; for $\mathrm{C} 3$ and $\mathrm{C} 4$, a real distribution of seismic stations- the
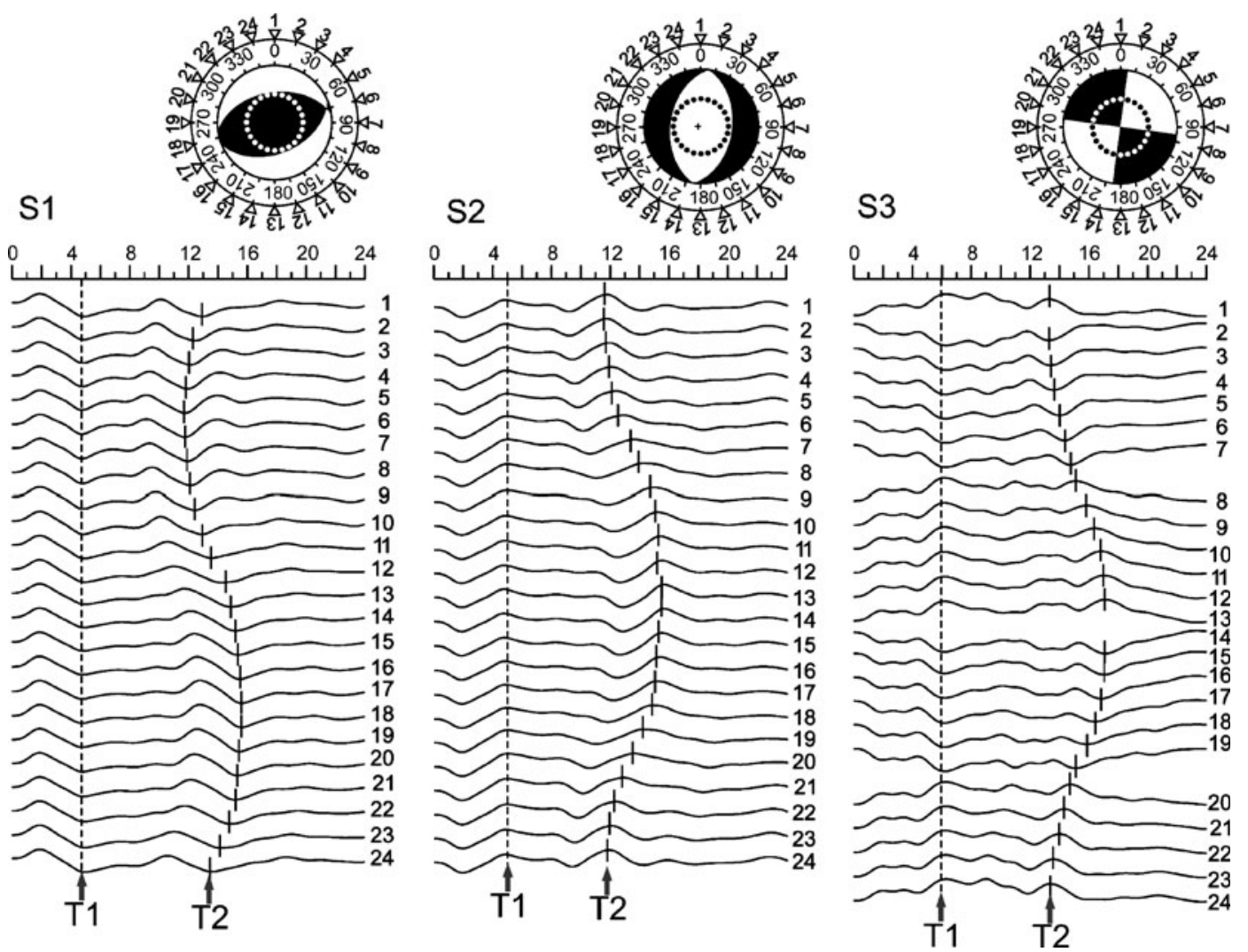

Fig. 6 Synthetic seismograms modeled for simple scenarios (S1, S2, and S3) generated with STF represented in Fig. 5a with normalized amplitudes. The seismograms are azimuthally aligned, and the code number of each receiver point is shown on the right. The receiver positions are marked in the top schemes by numbered inverted triangles on the angular scale and, in the focal sphere, by small open circles. The chosen common pulses are marked by a dashed line (T1) and vertical lines (T2). In S1, for the observation distance used $\left(30^{\circ}\right)$, all the receiver points are within compressive regions. As a result, the phase inversion effect due to the radiation pattern is not incorporated. This also occurs with scenario $\mathrm{S} 2$ relative to the dilatation regions. Scenario S3 corresponds to a strike-slip mechanism in which the crossed nodal zones produce an inversion of the phase polarity observed in the seismograms. For more details, see the text and Tables 1,2, and 8 
case study of the Arequipa (Peru) earthquakewas considered. Figures $6,7,8$, and 9 represent the waveforms for each scenario, where the chosen common pulses are marked as T1, T2,... (the time intervals between these pulses are provided in the "Appendix", Tables 8 and 9).

\subsection{Results}

The results of applying DIRDOP to the synthetic data are represented in Figs. 10,11, 12, and 13. For the scenarios in which the observation points are equidistant from the source (scenarios S1, S2, S3, $\mathrm{S} 6, \mathrm{C} 1$, and $\mathrm{C} 2$ ), the read delays coincide with the normalized ones. In the other four scenarios (S4, S5, C3, and C4), because the stations are located at different distances from the source, the delays needed to be normalized to a standard distance.

For all scenarios, the curve of the model (adjusted delays) was calculated from the rupture parameters (velocity, $v_{\mathrm{r}}$, and azimuth $\gamma$ ), which were obtained from $\Delta \tau^{*}$ by least squares fitting (Menke 1984). Table 2 and Figs. 10, 11, 12, and 13 summarize the results for each scenario.

\subsection{Simple scenarios}

For the simple scenarios in which the rupture velocity is defined only by a horizontal component (S1, S2, S3, S4, and S6), the estimated values of $\gamma$ and $v_{\mathrm{rH}}$ correspond precisely to the fault azimuth $\varphi$ and rupture velocity $v_{\mathrm{r}}$ (Table 2 ). The

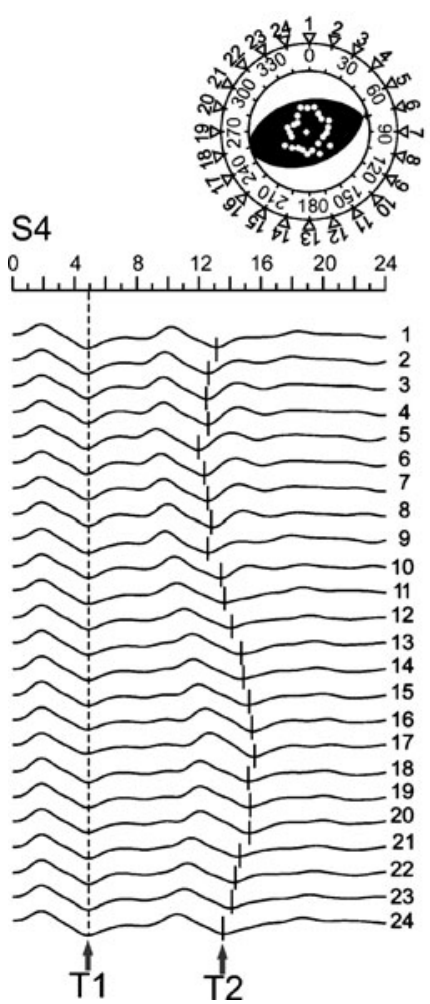

Fig. 7 Synthetic seismograms with a normalized amplitude relative to simple scenarios S4, S5, and S6 generated with STF represented in Fig. 5a, b. The seismograms are $a z-$ imuthally aligned, and the code number of each receiver point is shown on the right. The receiver positions are marked in the top schemes by numbered inverted triangles on the angular scale and, in the focal sphere, by small open circles. The selected common pulses are marked by
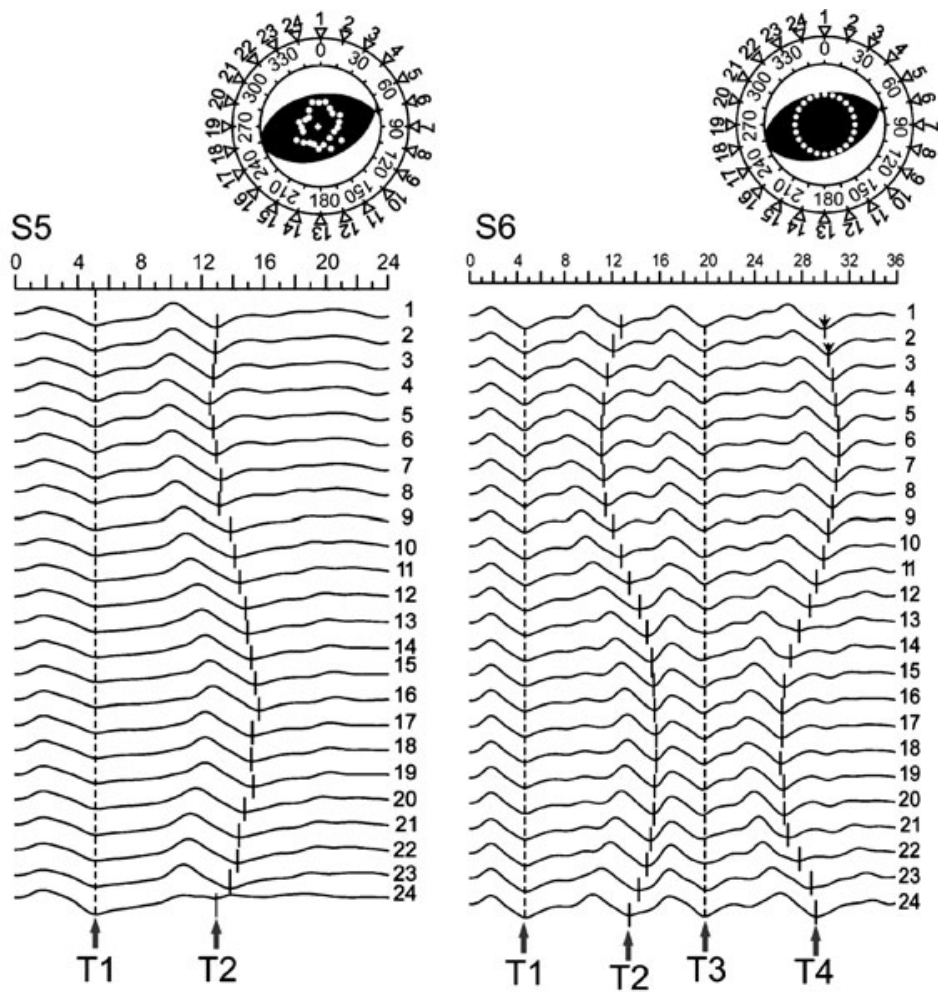

a dashed line (T1) and vertical lines (T2, T3, and $\mathrm{T} 4)$. Scenarios S4 and S5 describe unilateral extended ruptures with observation sites at variable distances (between $30^{\circ}$ and $90^{\circ}$ ). S4 describes a horizontal rupture and S5 an oblique rupture. $\mathrm{S} 6$ is a bilateral rupture, in which two steps are distinguished (T1-T2 and T3-T4). For more details, see the text and Tables 1, 2, and 8 


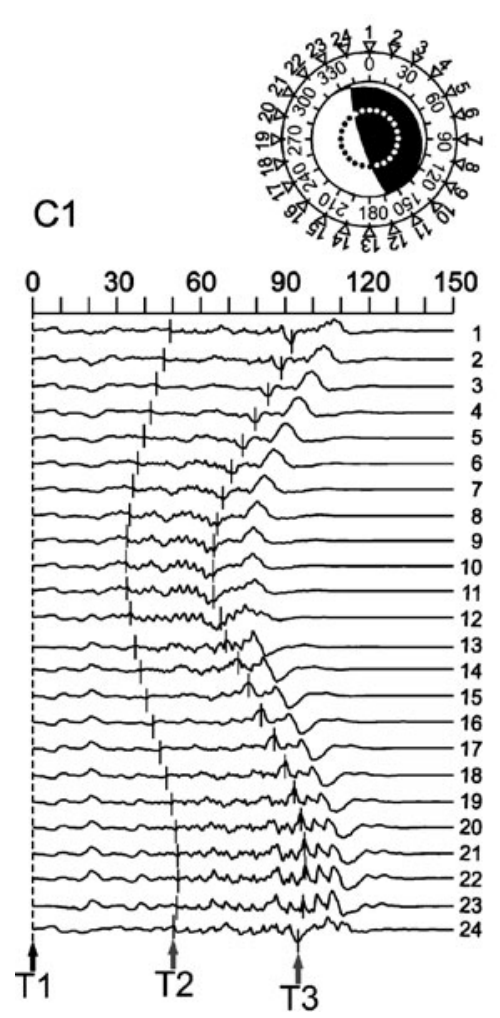

Fig. 8 Synthetic seismograms, with the amplitude normalized relative to complex scenarios $\mathrm{C} 1$ and $\mathrm{C} 2$, generated with a complex STF represented in Fig. 5c, d, respectively. The seismograms are azimuthally aligned, and the code number of each receiver point is shown on the right. The receiver positions are marked in the top schemes by numbered inverted triangles on the angular scale and, in the

results obtained by DIRDOP and the parameters used to compute the synthetic seismograms are in agreement. Concerning the rupture azimuth, the actual results show a better correlation with the expected ones than the error estimates would suggest (Table 2). Relative to the estimates of rupture velocity, the results are globally within the margin of error, except in S4, where we obtained a value that exceeded expectations by about $8 \%$ (in this case, the margin of error is $7 \%$ ). The calculation of rupture velocity because it is more complex (nonlinear inversion) is more sensitive to the parameters of the procedure and consequently more prone to errors.

Scenarios S1, S2, and S3 were used to test the sensitivity of different focal mechanisms. For this, we simulated similar horizontal ruptures but em-
C2
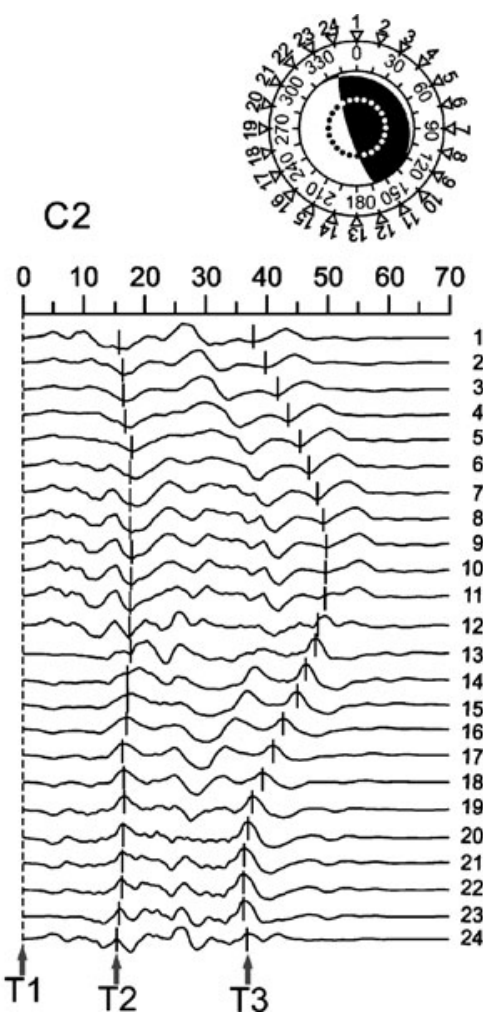

focal sphere, by small open circles. The selected common pulses are marked by a dashed line (T1) and vertical lines (T2, T3). Scenario C1 describes a unilateral rupture and C2 a bilateral rupture with observation sites at a fixed distance of $35^{\circ}$. For the two scenarios, two steps are distinguished (T1-T2 and T2-T3). For more details, see the text and Tables 1, 2, and 8

ployed different focal mechanisms (reverse, normal, and strike-slip). The results prove that this approach is insensitive to the focal mechanism.

The identification of common pulses on teleseismic data from dip-slip events is simplified. As adjacent azimuthal stations maintain polarity, the general aspects of seismograms are preserved, and as a consequence, recognizing common pulses is simpler. For strike-slip or oblique mechanisms, identification may become more difficult. The shape of the seismic trace completely changes when the nodal zones are crossed; this fact can complicate the identification of common pulses. This effect is visible in scenario S3 (Fig. 6).

In scenario S5, we wanted to test the influence of the vertical component of the rupture velocity on the inversion results and, consequently, ana- 
Fig. 9 Synthetic seismograms with a normalized amplitude, relative to complex scenarios $\mathrm{C} 3$ and $\mathrm{C} 4$ generated with STF represented in Fig. 5c. The seismograms are azimuthally aligned according the positions listed in Table 9. The chosen common pulses are marked by aligned to initial time line (T1) and vertical lines (T2, T3). Scenario C3 allows us to test the sensitivity of the method relative to a poor coverage of stations. In this case, we have used a rupture process, similar to that described in $\mathrm{C} 1$, but with a realistic station distribution that presents a gap of $60^{\circ}$. Scenario C4 tests the ability of the method to resolve low rupture velocities. For the two scenarios, two steps are distinguished (T1-T2 and T2-T3). For more details, see the text and Tables 1,2, and 9

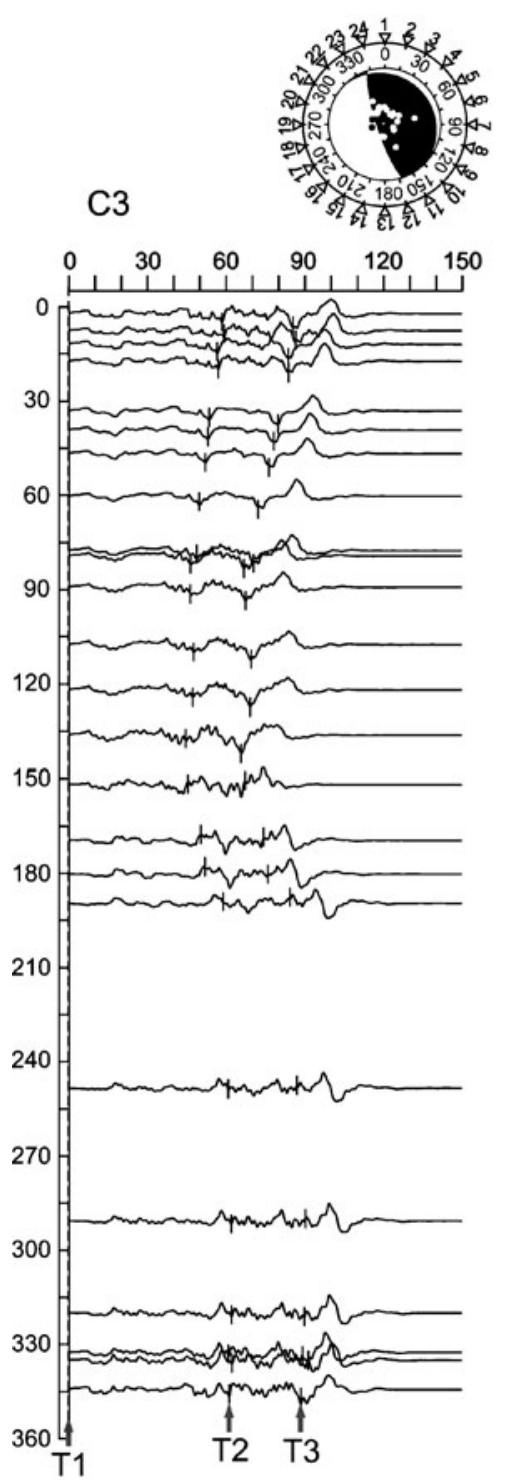

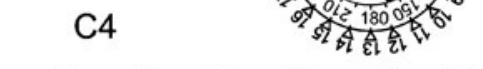

$\begin{array}{llllll}0 & 30 & 60 & 90 & 120 & 150\end{array}$

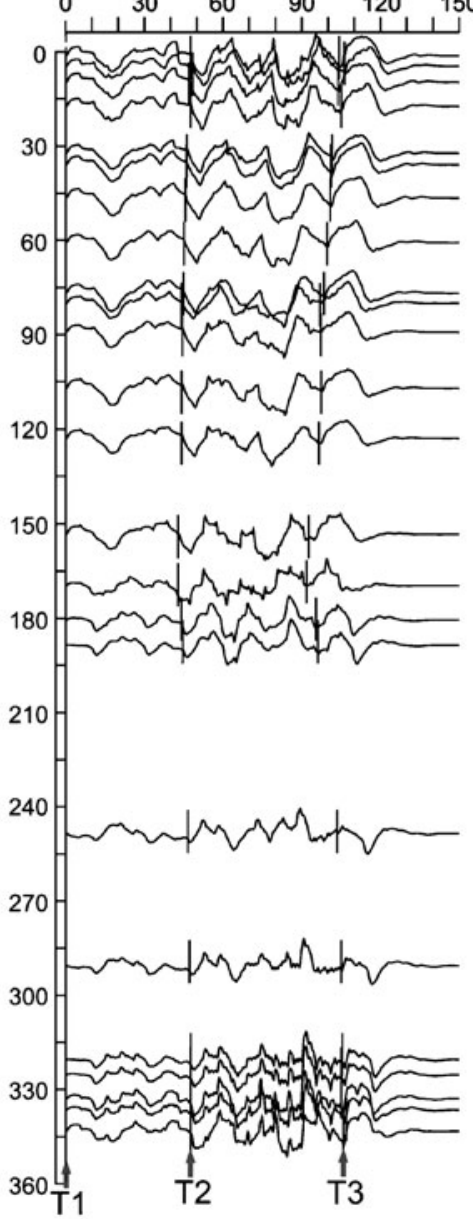

lyze the ability of the method to estimate this component of the rupture velocity. DIRDOP finds only the horizontal component of the rupture velocity vector $v_{\mathrm{rH}}$ and its errors (Fig. 4). However, if the azimuth and dip of the fault are known (determined by independent methods), $v_{\mathrm{r}}$ can be calculated within the allowed limits by the estimated errors of $v_{\mathrm{rH}}$ (Fig. 4). In this case, the $v_{\mathrm{r}}$ and the plunge angle $\left(\lambda_{\mathrm{r}}\right)$ obtained, respectively, from Eqs. 10 and 11 are $v_{\mathrm{r}}=2.7 \pm 0.30 \mathrm{~km} / \mathrm{s}$ and $\lambda_{\mathrm{r}}=$ $29.1 \pm 10^{\circ}$. These values are in agreement with those used in the rupture modeling represented in Table 1.
Scenario S6 refers to an asymmetric bilateral rupture. The bilateral effects are clearly shown in the synthetic seismograms (Fig. 7), where it is easy to identify two pairs of pulses related to the two stages of the rupture. The high quality of the results obtained for this case (Table 2) indicates the simplicity of the rupture.

\subsection{Complex scenarios}

For the unilateral rupture scenario $\mathrm{C} 1$ with regular coverage, the synthetic seismograms (Fig. 8) 


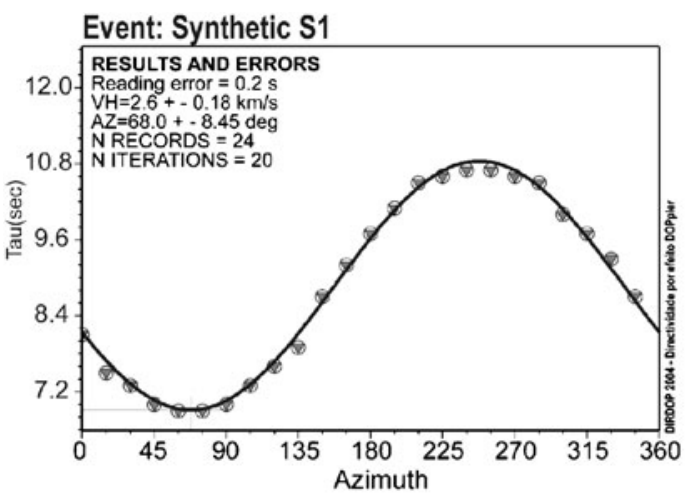

Event: Synthetic S3

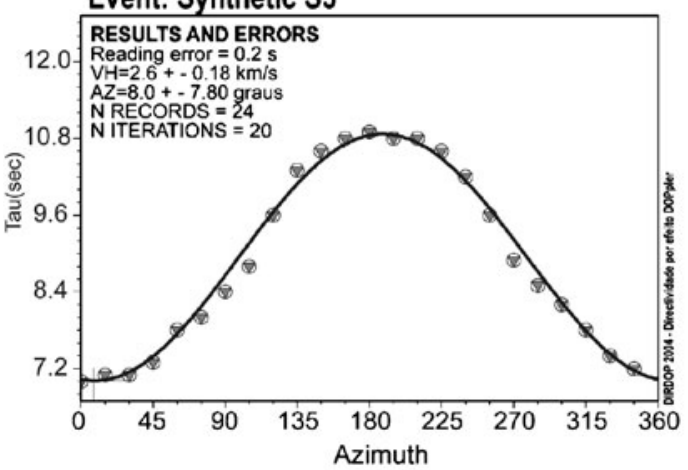

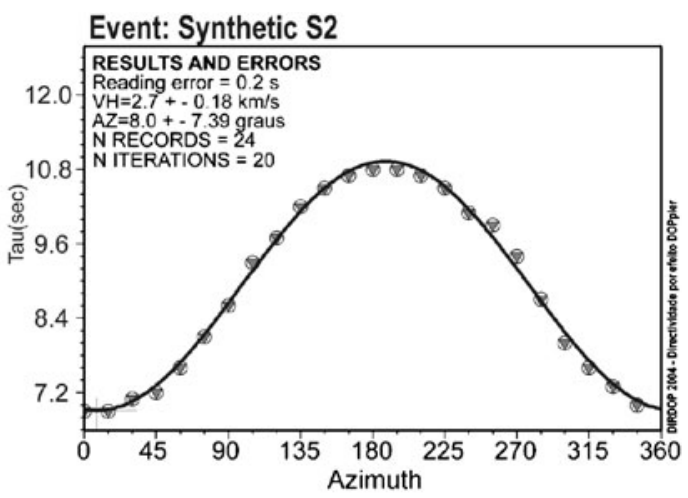

Event: Synthetic S4

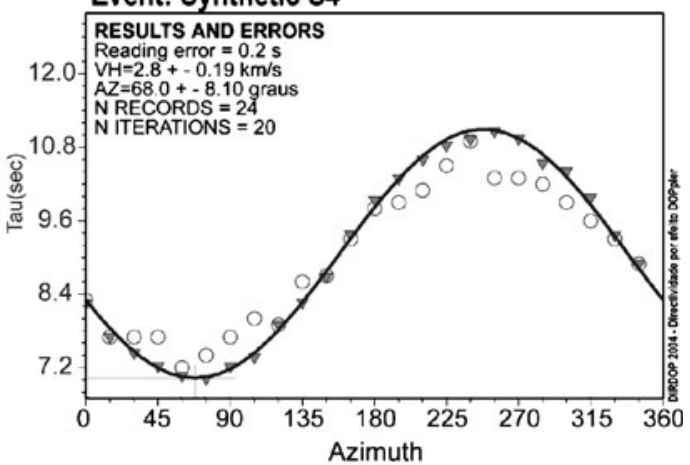

Pulse intervals read in seismograms

Pulse intervals normalized

Fit to normalized

Fig. 10 DIRDOP results for the simple scenarios S1, S2, S3, and S4. Plots of common time-delays versus azimuth of the receiver point. Open circles represent the time delays read in the synthetic waveforms of Figs. 6 and 7 and listed in Table 8. Triangles represent normalized pulse delays. The curves show the fit of the normalized pulse delays in relation to the parameters of the DIRDOP model. Note that the azimuth of the rupture corresponds to the minimum

are more complex when compared with similar ones from the simple situation S1 (Fig. 6). This fact does not increase the difficulty of identifying one or two pairs of common pulses. The estimated rupture velocity is equal to that used to generate the synthetic data; the errors in the rupture direction are of the same order of magnitude as the azimuth's gap $\left(15^{\circ}\right)$.

In the bilateral section of scenario $\mathrm{C} 2$ (the first $15 \mathrm{~s}$ ), we noted a discrepancy between the results and the parameters used in the simulation (Table 2). The estimated velocity $(1.0 \mathrm{~km} / \mathrm{s})$ is significantly lower than the expected value $(3.4 \mathrm{~km} / \mathrm{s})$, and the errors associated with the of this curve, marked by $A Z ; V H$ is the horizontal rupture velocity and is estimated using Eq. 6. In S1, S2, and S3, all observation points are at the same distance from the epicenter; one consequence of this is a coincidence between the read and normalized time delays. In S4, because the observation sites are at different hypocentral distances, this coincidence does not occur. The corresponding obtained values are listed in Table 8

direction of rupture are very high $\left(\sim 242^{\circ}\right)$ when compared with the stations gap. These results can be clearly observed in the wide dispersion of data in the theoretical curve (Fig. 12). To explain this, we suggest that when the rupture progresses simultaneously in more than one direction with equivalent energies, the interferences between the waves coming from different rupture fronts diminish the directive effects in the seismic records. In such scenarios, it is very difficult to identify the required common pulses with the necessary accuracy. This result suggests the failure of the method in cases of bilateral ruptures. Thus, in cases in which similar results are obtained (poor 

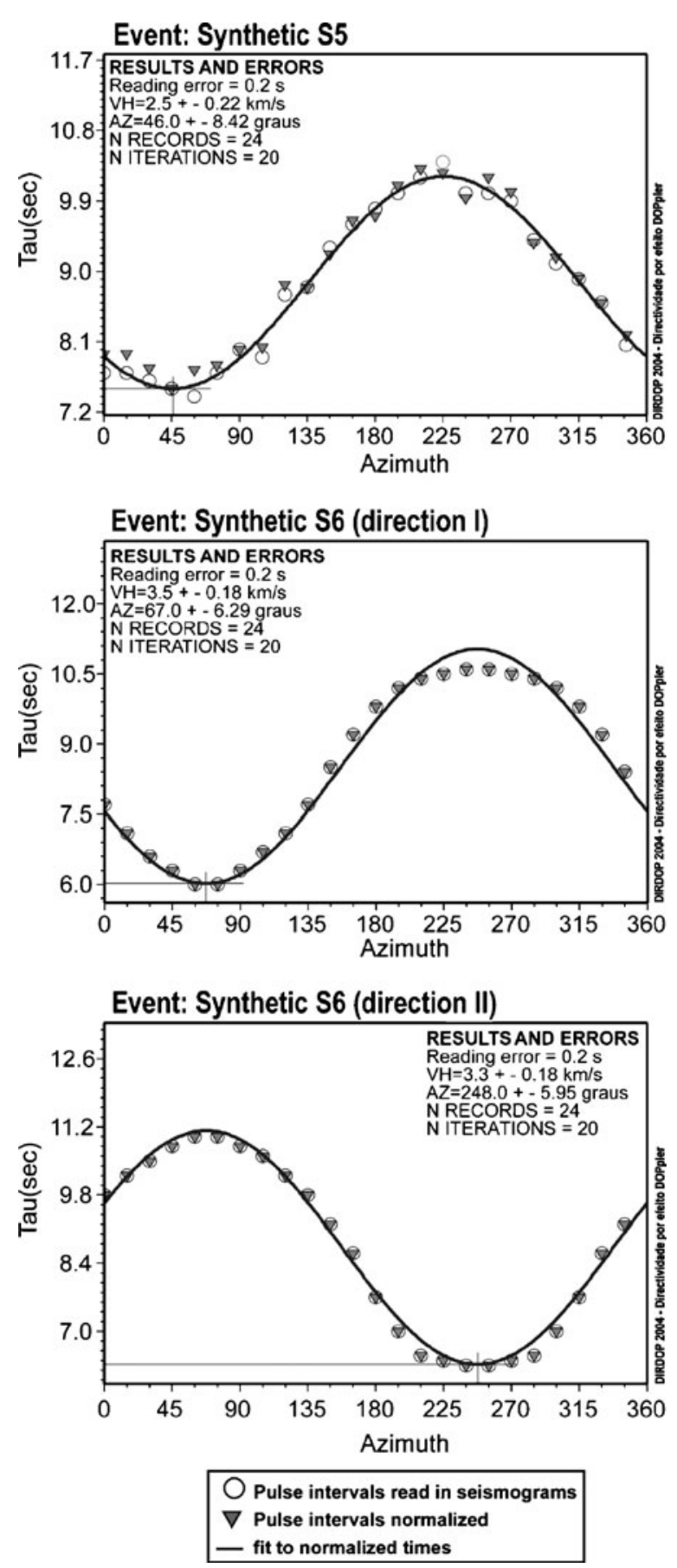

Fig. 11 Results for simple scenarios S5 and S6. Plots of pulse delay as a function of the azimuth of the receiver point. Open circles denote the read delays shown in Table 8; triangles represent the normalized read delays, and the curve shows the fit of the normalized delays to the model. $A Z$ denotes the rupture azimuth, which corresponds to the abscissa of the minimum of the curve; $V H$ is the rupture velocity calculated from Eq. 6. The corresponding obtained values are listed in Table 8 adjustment of the dataset to the theoretical model, unexpected values for the rupture velocity when compared with other sections of the same rupture, and direction errors much higher than in the station gap), they can be associated with bilateral or circular ruptures. In the last part of the rupture (17.5-35 s), which corresponds to a unidirectional section, the results fit well with the expected values, which allow us to conclude that this approach can also discriminate between sections of the rupture.

Scenario C3 allows us to test the sensitivity of the method relative to poor station coverage. To achieve this, we used a similar rupture scenario as described for $\mathrm{C} 1$ but with a realistic station distribution that presents a gap of $60^{\circ}$. As in scenario $\mathrm{C} 1$, the results (Fig. 13; Table 2) show consistency with the values used to generate the synthetic data. However, in scenario C3, the errors are larger and, in the direction of the rupture, display an order of magnitude of the gaps between stations.

Finally, scenario C4 tests the ability of the method to resolve low rupture velocities. The synthetic seismograms used (Fig. 9) exhibit the characteristic marks of directivity less obviously than in the other scenarios, but the difficult to identify common pulses do not increase. However, the numerical results and relative errors (Fig. 13; Table 2) show a larger mismatch between the expected values and the corresponding calculated values for the slow rupture.

The most significant conclusion of the tests is that in unilateral cases in which the common pulses are correctly identified, the errors associated with the rupture direction and rupture velocity depend on the angular coverage. We verify that the error associated with the rupture direction is, in general, of the same order of magnitude as the maximum azimuthal gap. For bilateral scenarios, the interference between the radiation arising from opposing sides of the rupture fronts makes the identification of common pulses difficult. As a consequence, the adjustment of the dataset to predictions of the theoretical model is poor and the error level increases. The analysis of the method allows us to conclude that if the gaps coincide with the azimuth of the extrema of Eq. 6, the constraint of this extrema fails, which can affect the estimate obtained for the rupture velocity. 


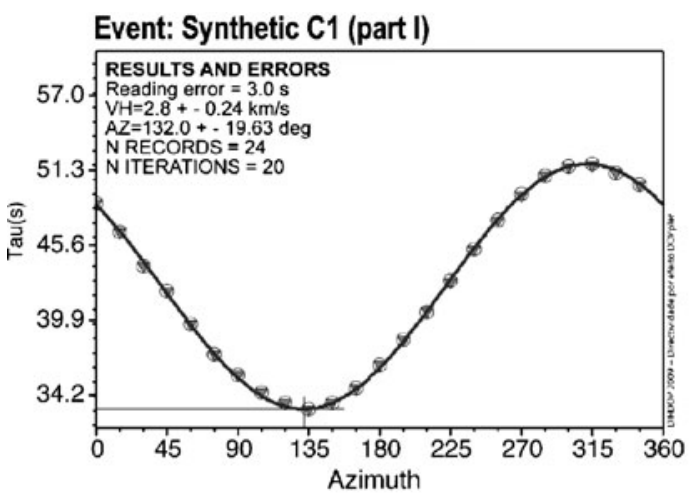

Event: Synthetic C2 (part I)

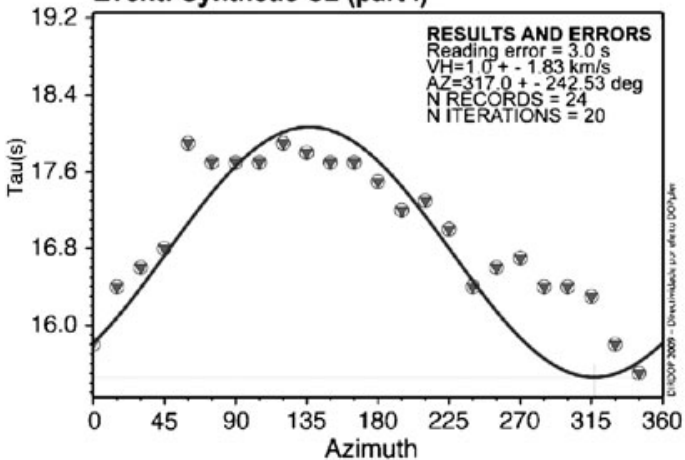

Pulse intervals read in seismograms

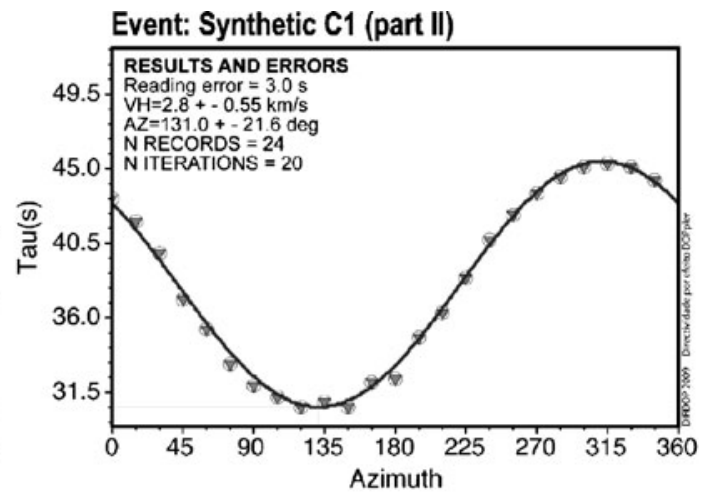

Event: Synthetic C2 (part II)

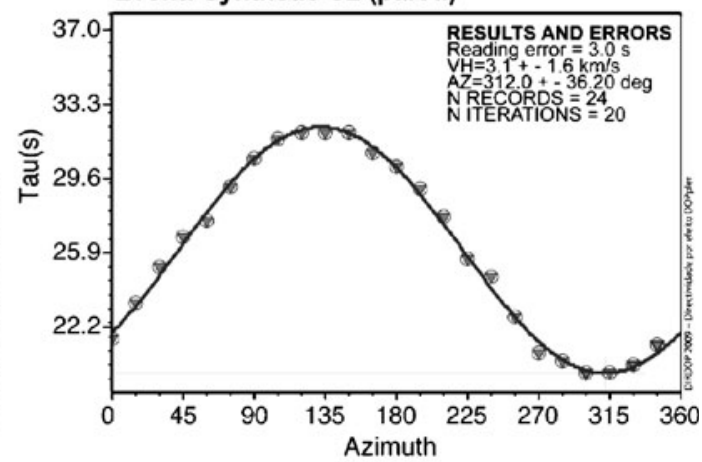

$\nabla$ Pulse intervals normalized

Fit to normalized

Fig. 12 Results for the complex scenarios $\mathrm{C} 1$ and $\mathrm{C} 2$. Plots of pulse delay as a function of the azimuth of the receiver point. Open circles denote the read delays shown in Table 8; triangles represent the normalized read delays, and the curve shows the fit of the normalized delays to the model. $A Z$ denotes the rupture azimuth, which corresponds to the abscissa of the minimum of the curve; $V H$ is the rupture velocity calculated from Eq. 6. The corresponding values obtained are listed in Table 8

According to the US Geological Survey (USGS), the hypocenter was at latitude $16.26^{\circ} \mathrm{S}$, longitude $73.64^{\circ} \mathrm{W}$, and had a depth of $33.0 \mathrm{~km}$. The Harvard Centroid Moment Tensor (CMT) mechanism solution (Fig. 14) indicates an inverse fault plane trending toward the NW with shallow dipping $\left(\right.$ strike $=318^{\circ} ; \operatorname{dip}=14^{\circ} ;$ rake $\left.=79^{\circ}\right)$. The spatiotemporal slip estimated by body wave inversion points to a unilateral rupture that propagated from NW to SE on a fault plane with an area of $180 \times 100 \mathrm{~km}^{2}$ (Bilek and Ruff 2002).

2. Denali, AK, USA $\left(M_{\mathrm{w}}=7.8\right.$; November 3 , 2002)

Most of the seismic activity in Alaska results from the interaction of the northwestward-moving Pacific plate with the corner of the North 


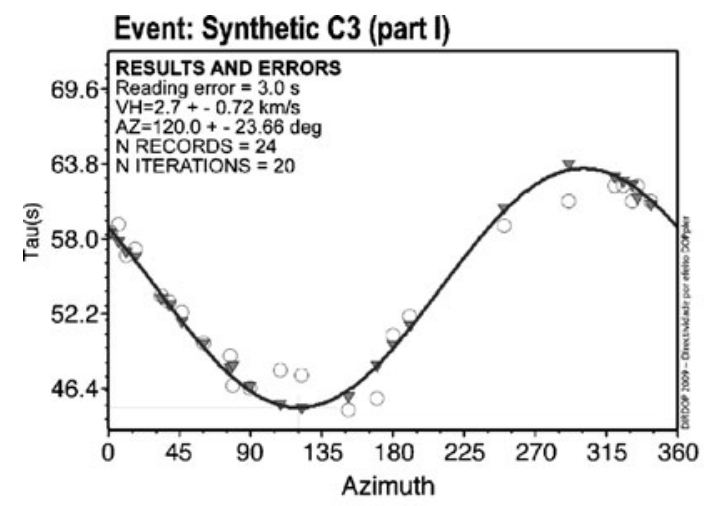

Event: Synthetic C4 (part I)

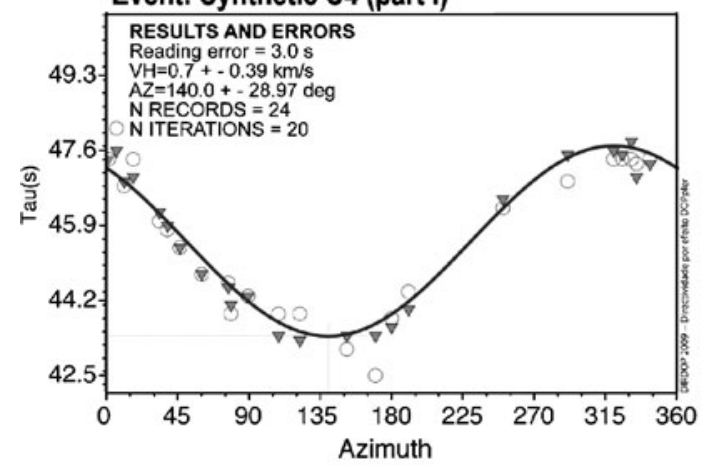

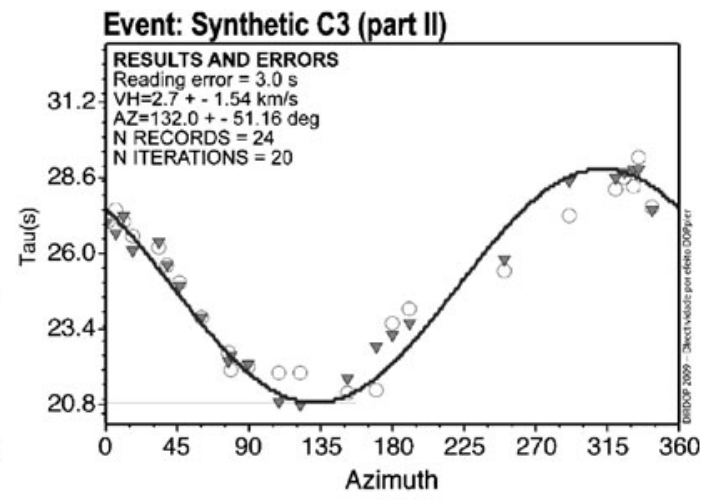

Event: Synthetic C4 (part II)

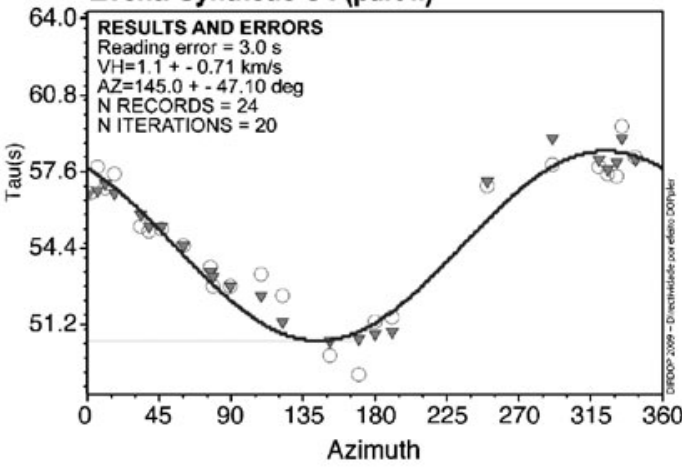

Pulse intervals read in seismograms $\quad \nabla$ Pulse intervals normalized

Fit to normalized

Fig. 13 Results for the complex scenarios C3 and C4. Plots of pulse delay as a function of the azimuth of the receiver point. Open circles denote the read delays shown in Table 9; triangles represent the normalized read delays, and the curve shows the fit of the normalized delays to the model. $A Z$ denotes the rupture azimuth, which corresponds to the abscissa of the minimum of the curve; $\mathrm{VH}$ is the rupture velocity calculated from Eq. 6. The corresponding values obtained are listed in Table 9

on the Black Rapids Glacier. According to the USGS, the hypocenter was at latitude $63.520^{\circ} \mathrm{N}$, longitude $147.530^{\circ} \mathrm{W}$, and had a depth of $5.0 \mathrm{~km}$. The Harvard CMT mechanism solution (Fig. 14) indicates a NW rupture plane $\left(\right.$ strike $=296^{\circ}$; dip $=$ $71^{\circ} ;$ rake $=171^{\circ}$ ). The source model, estimated by body wave inversion, points to a unilateral rupture that propagated from NW to SE on a fault plane with an area of $340 \times 15 \mathrm{~km}^{2}$ (Ozacar and Beck 2004).

3. Zemmouri-Boumerdes, Algeria $\left(M_{\mathrm{w}}=6.8\right.$; May 21, 2003)

This 2003 earthquake (Fig. 14), which was generated by a submarine fault, occurred at the boundary region between the Eurasian and African plates. From a geodynamic point of view, the curred in the Alaska Range, with the largest slide 
Table 2 Directivity parameters obtained for synthetic tests

\begin{tabular}{|c|c|c|c|c|}
\hline \multirow[t]{2}{*}{ Scenario } & \multicolumn{2}{|c|}{$\begin{array}{l}\text { Direction and rupture velocity used in } \\
\text { the rupture modeling }\end{array}$} & \multicolumn{2}{|c|}{$\begin{array}{l}\text { Direction and rupture velocity obtained by } \\
\text { method application }\end{array}$} \\
\hline & $\phi^{\mathrm{a}}(\mathrm{deg})$ & $v_{\mathrm{r}}^{\mathrm{a}}(\mathrm{km} / \mathrm{s})$ & $\gamma \pm \Delta \gamma^{\mathrm{a}}(\mathrm{deg})$ & $v_{\mathrm{rH}} \pm \Delta v_{\mathrm{rH}}^{\mathrm{a}}(\mathrm{km} / \mathrm{s})$ \\
\hline $\mathrm{S} 1$ & 67.5 & 2.60 & $68.0 \pm 8.45$ & $2.6 \pm 0.18$ \\
\hline $\mathrm{S} 2$ & 7.5 & 2.60 & $8.0 \pm 7.39$ & $2.7 \pm 0.18$ \\
\hline S3 & 7.5 & 2.50 & $8.0 \pm 7.80$ & $2.6 \pm 0.18$ \\
\hline S4 & 67.5 & 2.60 & $68.0 \pm 8.10$ & $2.8 \pm 0.19$ \\
\hline S5 & 52.5 & 2.80 & $46.0 \pm 8.42$ & $2.5 \pm 0.22$ \\
\hline \multirow[t]{2}{*}{ S6 (bilateral) } & $67.5^{\mathrm{b}}$ & 3.55 & $67.0 \pm 6.20^{\mathrm{b}}$ & $3.5 \pm 0.18$ \\
\hline & $247.5^{\mathrm{c}}$ & & $248.0 \pm 5.95^{\mathrm{c}}$ & $3.3 \pm 0.18$ \\
\hline \multirow[t]{2}{*}{$\mathrm{C} 1$} & 132.0 & 2.8 & $132.0 \pm 19.63$ & $2.8 \pm 0.18$ \\
\hline & & & $131.0 \pm 21.60$ & $2.8 \pm 0.55$ \\
\hline \multirow[t]{2}{*}{$\mathrm{C} 2$} & 312.0 and $^{\mathrm{d}} 132.0$ & 3.4 & $317.0 \pm 242.53$ & $1.0 \pm 1.83$ \\
\hline & $312^{\mathrm{e}}$ & & $312.0 \pm 36.20$ & $3.1 \pm 1.6$ \\
\hline \multirow[t]{2}{*}{$\mathrm{C} 3$} & 132.0 & 2.7 & $120.0 \pm 23.66$ & $2.7 \pm 0.72$ \\
\hline & & & $132.0 \pm 51.16$ & $2.7 \pm 1.54$ \\
\hline \multirow[t]{2}{*}{$\mathrm{C} 4$} & 132.0 & 1.0 & $140.0 \pm 28.97$ & $0.7 \pm 0.39$ \\
\hline & & & $145.0 \pm 47.10$ & $1.1 \pm 0.71$ \\
\hline
\end{tabular}

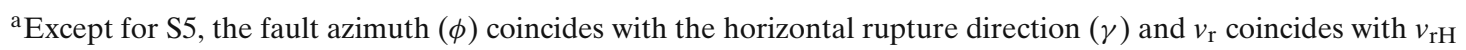

${ }^{\mathrm{b}}$ First step of rupture

'Second step of rupture

${ }^{\mathrm{d}}$ Bilateral part between 0 and $15 \mathrm{~s}$

${ }^{\mathrm{e}}$ Unilateral part between 15 and $35 \mathrm{~s}$

Mediterranean basin shows a collision process between these two tectonic plates in the NW-SE direction. The shortening rate, estimated previously for the 2003 event, is about $2.5 \mathrm{~mm} /$ year (Buforn et al. 2004). These relative plate motions create a compressional tectonic environment with mostly thrust-faulting and strike-slip fault- ing mechanisms (Bezzeghoud and Buforn 1999). The Tellian Atlas (the major geological feature in northern Algeria) is characterized by reverse faults trending in a NE-SW direction; other types of faults, such as normal and strike-slip faults, are present in different seismogenic zones of northern Algeria (Bezzeghoud and Buforn 1999).

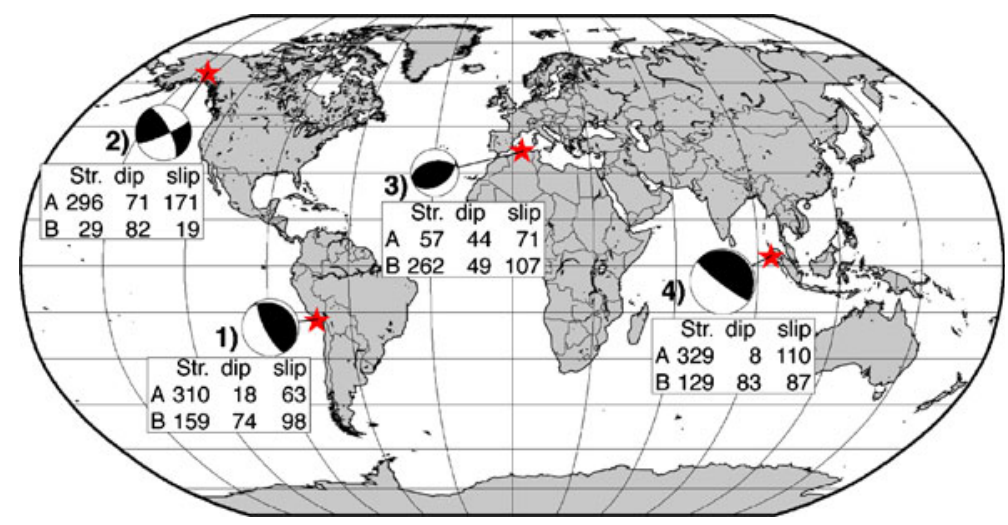

Fig. 14 Map of the studied earthquakes: 1 Arequipa, Peru $\left(M_{\mathrm{w}}=8.4\right.$; June 23,2001$) ; 2$ Denali, AK, USA $\left(M_{\mathrm{w}}=\right.$ 7.8; November 3, 2002); 3 Zemmouri-Boumerdes, Algeria
$\left(M_{\mathrm{w}}=6.8\right.$; May 21,2003$) ; 4$ Sumatra, Indonesia $\left(M_{\mathrm{w}}=\right.$ 9.3; December 26, 2004). Main shock focal mechanisms are taken from the Harvard CMT catalog 
This $M_{\mathrm{w}}=6.8$ event was located offshore at $37.02^{\circ} \mathrm{N}$ and $3.77^{\circ} \mathrm{E}$ and a focal depth of $7 \mathrm{~km}$ in a zone characterized by relatively moderate and diffuse seismicity (Ayadi et al. 2003). The main shock has been relocated using HypoDD (Ayadi et al. 2008) at Zemmouri el Bahri village, close to the continent, at $36.83^{\circ} \mathrm{N}$ and $3.65^{\circ} \mathrm{E}$. This earthquake is the second largest to occur in Algeria since the $1980 \mathrm{El}$ Asnam $M_{\mathrm{s}}=7.3$ earthquake. In the epicentral area, the main shock severely affected the towns and villages, particularly the coastal towns of Zemmouri and Boumerdes. The earthquake killed 2,271 people, injured 11,455 (official toll), and caused great damage, mainly to the cities of Boumerdes, Algiers, and Dellys. The Harvard CMT mechanism solution (Fig. 14) indicates an ENE-WSW rupture plane $\left(\right.$ strike $=57^{\circ} ; \operatorname{dip}=44^{\circ} ;$ rake $\left.=71^{\circ}\right)$. The source model, estimated by joint inversion of body wave and teleseismic data, points to a bilateral rupture that propagated from the hypocenter on a fault plane with an area of $60 \times 24 \mathrm{~km}^{2}$ (Delouis et al. 2004).
4. Sumatra, Indonesia (the strongest earthquake; $M_{\mathrm{w}}=9.3$; December 26, 2004)

This megathrust-faulting earthquake $\left(M_{\mathrm{w}}=9.3\right)$ occurred at the interface of the India and Burma plates along the Sunda Trench fault line and was caused by the release of stresses that developed as the India plate subducted beneath the overriding Burma plates. The two plates are converging (dextral-oblique convergence) at a rate of $6 \mathrm{~cm} /$ year (Tregoning et al. 1994), and the complex tectonics of the region involve several plates, including the Australia, Sunda, Eurasia, India, and Burma plates (i.e., Bilham et al. 2005). Due to this elevated convergence rate, the region in which both earthquakes occurred is one of the world's most seismically active regions. This earthquake triggered a massive tsunami that affected several countries throughout South and Southeast Asia, including Indonesia, Sri Lanka, India, Thailand, Somalia, Myanmar, Malaysia, Maldives, Tanzania, and Bangladesh. The tsunami crossed into the Pacific Ocean and was recorded along
Table 3 Phases Peru

Distribution of the seismic stations and measured time of common pulses for the Arequipa, Peru earthquake $\left(M_{\mathrm{w}}=8.4\right.$; June 23, 2001)

\begin{tabular}{|c|c|c|c|c|c|}
\hline \multirow[t]{2}{*}{ Station name } & \multirow{2}{*}{$\begin{array}{l}\text { Azimuth } \\
\text { (deg) }\end{array}$} & \multirow[t]{2}{*}{$\Delta(\operatorname{deg})$} & \multicolumn{3}{|c|}{ Time of common pulses used (s) } \\
\hline & & & $\mathrm{T} 1$ & $\mathrm{~T} 2$ & $\mathrm{~T} 3$ \\
\hline HRV & 1.51 & 58.67 & 0.00 & 51.45 & 96.12 \\
\hline SDV & 6.24 & 25.16 & 0.00 & 51.03 & 96.14 \\
\hline DRLN & 11.15 & 66.88 & 0.00 & 47.45 & 92.83 \\
\hline FDF & 16.81 & 32.17 & 0.00 & 45.07 & 92.65 \\
\hline DSB & 33.40 & 89.86 & 0.00 & 44.76 & 86.20 \\
\hline CMLA & 38.51 & 70.12 & 0.00 & 44.28 & 84.95 \\
\hline PAB & 46.26 & 89.90 & 0.00 & 44.07 & 83.56 \\
\hline SACV & 60.21 & 58.10 & 0.00 & 39.88 & 74.17 \\
\hline DBIC & 77.02 & 71.45 & 0.00 & 38.80 & 72.34 \\
\hline RCBR & 78.58 & 38.07 & 0.00 & 38.31 & 71.19 \\
\hline ASCN & 89.36 & 58.06 & 0.00 & 36.96 & 70.54 \\
\hline TSUM & 108.72 & 85.56 & 0.00 & 38.63 & 70.02 \\
\hline SUR & 122.24 & 84.80 & 0.00 & 39.19 & 69.69 \\
\hline HOPE & 151.71 & 47.57 & 0.00 & 38.49 & 65.75 \\
\hline NIEB & 169.82 & 20.26 & 0.00 & 40.29 & 65.73 \\
\hline SPA & 180.00 & 73.86 & 0.00 & 42.95 & 74.18 \\
\hline SBA & 190.67 & 80.16 & 0.00 & 42.10 & 77.29 \\
\hline RAR & 250.41 & 80.97 & 0.00 & 51.85 & 91.34 \\
\hline POHA & 291.14 & 88.35 & 0.00 & 53.17 & 94.81 \\
\hline PAS & 320.27 & 65.96 & 0.00 & 55.32 & 96.62 \\
\hline WUAZ & 325.82 & 62.70 & 0.00 & 54.09 & 97.42 \\
\hline NEW & 331.54 & 75.28 & 0.00 & 52.85 & 97.30 \\
\hline HKT & 334.70 & 50.96 & 0.00 & 54.84 & 99.25 \\
\hline CCM & 343.14 & 56.75 & 0.00 & 52.82 & 98.64 \\
\hline
\end{tabular}


the west coast of South and North America. The Harvard CMT mechanism (Fig. 14) revealed a SSE-NNW rupture plane $\left(\right.$ strike $=329^{\circ}$; dip $=$ $8^{\circ}$; rake $=110^{\circ}$ ). Using data collected by the German Regional Seismic Network and applying array techniques, Krüger and Ohrnberger $(2005 \mathrm{a}, \mathrm{b})$ find a total rupture length of $1,150 \mathrm{~km}$. From the epicenter $\left(3.316^{\circ} \mathrm{N}, 95.854^{\circ} \mathrm{E}\right.$, USGS), the rupture extended 1,200-1,300 $\mathrm{km}$ along the Sunda Trench toward the north-northwest (Ammon et al. 2005; Ni et al. 2005; Vigny et al. 2005 ) with a downdip width of $\sim 200 \mathrm{~km}$ (Ammon et al. 2005).

\subsection{Data}

The most delicate and painstaking step involved in applying the method to real data is identifying common pulses in all seismograms. Given a set of seismograms that record an earthquake at several stations around the source, it is often difficult to recognize common seismic pulses. This difficulty is due mainly to a combination of three factors: (a) interference with phases of other subevents that could mask the sought-after pulse, (b) pulse shifts due to differences in the epicentral distance, and (c) the influence of the radiation pattern. Therefore, this step requires the selection of criteria based on practical experience with seismogram analyses. A good azimuth distribution of high quality waveforms is the first requirement. After being azimuthally ordered and aligned by the time of arrival of the $\mathrm{P}$ wave, the waveforms must reveal some common pulses that can be followed on almost all of the seismograms. When a particular phase is followed across a set of seis-
Table 4 Phases Alaska

Distribution of the seismic stations and measured time of common pulses for the Denali, AK, USA earthquake $\left(M_{\mathrm{w}}=7.8\right.$; November 3, 2002)

\begin{tabular}{|c|c|c|c|c|c|}
\hline \multirow[t]{2}{*}{ Station name } & \multirow{2}{*}{$\begin{array}{l}\text { Azimuth } \\
\text { (deg) }\end{array}$} & \multirow[t]{2}{*}{$\Delta(\operatorname{deg})$} & \multicolumn{3}{|c|}{ Time of common pulses used (s) } \\
\hline & & & $\mathrm{T} 1$ & $\mathrm{~T} 2$ & $\mathrm{~T} 3$ \\
\hline TRTE & 3.47 & 58.13 & 0.00 & 6.20 & 61.89 \\
\hline RUE & 12.58 & 63.22 & 0.00 & 6.30 & 60.40 \\
\hline KONO & 13.73 & 55.72 & 0.00 & 6.30 & 60.20 \\
\hline CART & 26.77 & 75.60 & 0.00 & 6.60 & 58.90 \\
\hline MTE & 31.07 & 71.49 & 0.00 & 6.80 & 58.20 \\
\hline SFJ & 40.77 & 36.67 & 0.00 & 6.40 & 54.50 \\
\hline DRLN & 62.72 & 47.49 & 0.00 & 6.80 & 49.60 \\
\hline LBNH & 77.78 & 45.47 & 0.00 & 6.70 & 45.90 \\
\hline BBSR & 80.24 & 58.46 & 0.00 & 6.70 & 47.10 \\
\hline PAL & 82.06 & 47.20 & 0.00 & 7.00 & 46.00 \\
\hline MYNC & 95.65 & 47.56 & 0.00 & 6.30 & 43.70 \\
\hline CCM & 100.15 & 41.94 & 0.00 & 6.50 & 43.20 \\
\hline WMOK & 110.54 & 41.51 & 0.00 & 6.30 & 42.90 \\
\hline TX32 & 119.66 & 44.29 & 0.00 & 6.20 & 44.00 \\
\hline SDD & 133.95 & 35.48 & 0.00 & 5.80 & 44.70 \\
\hline SBC & 136.14 & 34.02 & 0.00 & 5.80 & 44.90 \\
\hline PTCN & 164.09 & 89.60 & 0.00 & 6.30 & 54.00 \\
\hline POHA & 190.61 & 44.28 & 0.00 & 5.50 & 56.90 \\
\hline KIP & 194.21 & 42.87 & 0.00 & 5.00 & 57.20 \\
\hline MIDW & 222.47 & 40.34 & 0.00 & 6.70 & 63.80 \\
\hline KWAJ & 231.07 & 63.34 & 0.00 & 6.40 & 63.10 \\
\hline WAKE & 236.61 & 54.01 & 0.00 & 6.40 & 64.70 \\
\hline PMG & 243.65 & 87.77 & 0.00 & 6.00 & 63.10 \\
\hline MAJO & 274.88 & 51.02 & 0.00 & 5.10 & 70.10 \\
\hline MDJ & 288.01 & 48.15 & 0.00 & 5.60 & 70.10 \\
\hline BJT & 295.15 & 57.52 & 0.00 & 5.80 & 68.20 \\
\hline KURK & 328.04 & 60.26 & 0.00 & 6.00 & 66.90 \\
\hline CHK & 334.57 & 59.19 & 0.00 & 5.80 & 66.50 \\
\hline ANTO & 359.62 & 76.73 & 0.00 & 5.90 & 61.60 \\
\hline
\end{tabular}


mograms, its shape changes. The level of these variations is such that, in some cases, we can even note polarity inversions, in particular when nodal zones are crossed. Sometimes, the identification of "difficult pulses" must be facilitated through the use of theoretical travel times and the radiation pattern.

For the four applications described previously, we used teleseismic broadband vertical waveforms supplied by the Incorporated Research Institutions for Seismology Data Management Center consortium. The selected stations are located at distances between $30^{\circ}$ and $90^{\circ}$ from the epicenter. Tables 3, 4, 5, and 6 provide complete information regarding the stations used (name, azimuth, and epicentral distance), as well as the time of common pulses used in the inversion for each seismic event:

1. Arequipa, Peru $\left(M_{\mathrm{w}}=8.4\right.$; June 23,2001$)$

For the Arequipa directivity study, data from 24 stations span an azimuthal coverage with an average angular interval of $15^{\circ}$ and a major gap of $59.74^{\circ}$ southwest of the epicenter, between stations SBA and RAR (Table 3). In the selected waveforms represented in Fig. 15, we applied the above criteria and identified three common pulses indicated by $\mathrm{T} 1, \mathrm{~T} 2$, and $\mathrm{T} 3$. The seismograms after the last phase identified ( $\sim 82 \mathrm{~s})$ become too complex to permit clear identification of other common pulses. Reading errors in the seismograms of $1.5 \mathrm{~s}$ were assumed.
Table 5 Phases Algeria

Distribution of the seismic stations and measured time of common pulses for the Zemmouri-Boumerdes, Algeria earthquake $\left(M_{\mathrm{w}}=6.8\right.$; May 21, 2003)

\begin{tabular}{|c|c|c|c|c|c|}
\hline \multirow[t]{2}{*}{ Station name } & \multirow{2}{*}{$\begin{array}{l}\text { Azimuth } \\
\text { (deg) }\end{array}$} & \multirow[t]{2}{*}{$\Delta(\mathrm{deg})$} & \multicolumn{3}{|c|}{ Time of common pulses used (s) } \\
\hline & & & $\mathrm{T} 1$ & $\mathrm{~T} 2$ & T3 \\
\hline KBS & 2.34 & 42.28 & 0.0 & 4.8 & $\overline{11.8}$ \\
\hline BILL & 6.67 & 74.55 & 0.0 & 5.5 & 11.4 \\
\hline MA2 & 16.35 & 80.07 & 0.0 & 4.6 & 11.4 \\
\hline YSS & 26.72 & 88.79 & 0.0 & 4.7 & 11.6 \\
\hline HIA & 37.16 & 77.19 & 0.0 & 4.4 & 11.8 \\
\hline TLY & 41.59 & 67.53 & 0.0 & 4.3 & 13.2 \\
\hline BJT & 45.89 & 81.47 & 0.0 & 4.4 & 13.1 \\
\hline $\mathrm{CHK}$ & 47.31 & 48.08 & 0.0 & 4.1 & 13.6 \\
\hline ENH & 56.94 & 83.57 & 0.0 & 4.2 & 13.6 \\
\hline AAK & 60.42 & 53.22 & 0.0 & 4.1 & 13.9 \\
\hline QIZ & 65.40 & 90.92 & 0.0 & 4.4 & 13.3 \\
\hline LSA & 66.87 & 70.93 & 0.0 & 4.1 & 13.7 \\
\hline KMBO & 133.00 & 48.93 & 0.0 & 4.3 & 13.1 \\
\hline MBAR & 140.05 & 44.90 & 0.0 & 4.4 & 13.2 \\
\hline LSZ & 151.52 & 56.77 & 0.0 & 4.6 & 12.2 \\
\hline LBTB & 158.14 & 64.92 & 0.0 & 4.7 & 12.0 \\
\hline SUR & 164.78 & 70.73 & 0.0 & 4.9 & 11.8 \\
\hline DBIC & 196.79 & 31.10 & 0.0 & 4.9 & 10.7 \\
\hline RCBR & 229.71 & 56.39 & 0.0 & 5.8 & 10.2 \\
\hline LPAZ & 246.30 & 85.73 & 0.0 & 5.8 & 10.5 \\
\hline SAML & 248.67 & 77.43 & 0.0 & 5.8 & 10.6 \\
\hline OTAV & 265.53 & 83.64 & 0.0 & 5.9 & 10.1 \\
\hline BBSR & 287.06 & 55.43 & 0.0 & 5.8 & 10.8 \\
\hline GOGA & 296.43 & 68.91 & 0.0 & 5.7 & 11.3 \\
\hline DRLN & 306.00 & 45.26 & 0.0 & 5.5 & 10.9 \\
\hline ANMO & 309.13 & 83.51 & 0.0 & 5.6 & 11.1 \\
\hline $\mathrm{BOZ}$ & 319.86 & 79.36 & 0.0 & 5.3 & 11.1 \\
\hline FRB & 326.38 & 49.94 & 0.0 & 5.9 & 11.6 \\
\hline INK & 344.47 & 70.38 & 0.0 & 5.1 & 11.6 \\
\hline COLA & 347.94 & 76.15 & 0.0 & 5.1 & 11.8 \\
\hline
\end{tabular}


Table 6 Phases Sumatra

\begin{tabular}{|c|c|c|c|c|c|c|c|}
\hline \multirow[t]{2}{*}{ Station name } & \multirow{2}{*}{$\begin{array}{l}\text { Azimuth } \\
\text { (deg) }\end{array}$} & \multirow[t]{2}{*}{$\Delta(\mathrm{deg})$} & \multicolumn{5}{|c|}{ Time of common pulses used (s) } \\
\hline & & & T1 & $\mathrm{T} 2$ & T3 & $\mathrm{T} 4$ & T5 \\
\hline TLY & 6.35 & 48.65 & 0.00 & 31.64 & 90.71 & 174.69 & 220.74 \\
\hline TIXI & 10.46 & 71.35 & 0.00 & 31.53 & 90.67 & 175.03 & 222.71 \\
\hline CHTO & 10.56 & 15.68 & 0.00 & 29.48 & 85.98 & 170.73 & 216.15 \\
\hline KMI & 16.08 & 22.66 & 0.00 & 31.98 & 90.81 & 177.01 & 223.43 \\
\hline XAN & 20.04 & 32.88 & 0.00 & 32.50 & 92.16 & 179.02 & 224.95 \\
\hline BJT & 23.02 & 40.87 & 0.00 & 33.13 & 92.14 & 179.66 & 227.54 \\
\hline MDJ & 30.74 & 50.67 & 0.00 & 34.26 & 92.47 & 178.67 & 228.24 \\
\hline YSS & 35.16 & 59.34 & 0.00 & 33.97 & 95.05 & 181.40 & 231.59 \\
\hline QIZ & 39.89 & 20.69 & 0.00 & 34.09 & 94.13 & 186.29 & 237.15 \\
\hline KMNB & 43.73 & 30.16 & 0.00 & 34.25 & 95.44 & 184.62 & 240.42 \\
\hline SSLB & 47.61 & 31.58 & 0.00 & 33.96 & 99.74 & 188.58 & 243.80 \\
\hline TPUB & 48.02 & 31.05 & 0.00 & 34.81 & 100.08 & 189.26 & 245.29 \\
\hline YULB & 48.57 & 31.60 & 0.00 & 34.34 & 99.74 & 188.92 & 244.62 \\
\hline TWGB & 49.25 & 31.11 & 0.00 & 33.89 & 97.79 & 188.22 & 243.99 \\
\hline GUMO & 75.02 & 49.53 & 0.00 & 37.30 & 103.75 & 200.56 & 260.75 \\
\hline DAV & 81.55 & 29.71 & 0.00 & 36.27 & 102.70 & 200.83 & 263.71 \\
\hline HNR & 101.93 & 64.97 & 0.00 & 39.17 & 106.23 & 204.51 & 266.32 \\
\hline PMG & 104.36 & 52.73 & 0.00 & 39.47 & 109.48 & 209.00 & 271.51 \\
\hline CTAO & 117.43 & 54.53 & 0.00 & 38.97 & 109.73 & 210.23 & 274.83 \\
\hline EIDS & 121.52 & 60.50 & 0.00 & 39.32 & 110.36 & 208.82 & 274.80 \\
\hline WRAB & 123.08 & 44.19 & 0.00 & 38.96 & 110.02 & 209.81 & 274.12 \\
\hline ARMA & 126.66 & 62.75 & 0.00 & 39.41 & 110.03 & 209.32 & 270.05 \\
\hline STKA & 132.58 & 55.66 & 0.00 & 39.89 & 110.24 & 209.76 & 273.33 \\
\hline TOO & 136.45 & 61.29 & 0.00 & 38.72 & 106.72 & 205.26 & 271.94 \\
\hline MBWA & 136.70 & 33.65 & 0.00 & 39.82 & 111.34 & 211.68 & 275.53 \\
\hline TAU & 140.80 & 65.20 & 0.00 & 39.23 & 109.40 & 207.15 & 270.37 \\
\hline KMBL & 146.34 & 42.38 & 0.00 & 39.54 & 108.69 & 209.69 & 275.28 \\
\hline BLDU & 151.07 & 39.10 & 0.00 & 40.69 & 110.02 & 210.14 & 276.52 \\
\hline NWAO & 152.47 & 41.27 & 0.00 & 40.34 & 109.66 & 208.03 & 273.72 \\
\hline DRV & 163.46 & 76.49 & 0.00 & 38.16 & 106.08 & 201.46 & 261.80 \\
\hline SBA & 168.46 & 89.21 & 0.00 & 36.38 & 103.16 & 196.38 & 256.94 \\
\hline CASY & 173.80 & 70.20 & 0.00 & 38.10 & 105.04 & 199.55 & 262.21 \\
\hline AIS & 200.99 & 44.31 & 0.00 & 37.63 & 98.77 & 187.95 & 250.01 \\
\hline SUR & 236.35 & 79.29 & 0.00 & 35.48 & 94.80 & 178.34 & 235.44 \\
\hline BOSA & 239.33 & 74.78 & 0.00 & 35.47 & 95.46 & 177.34 & 235.36 \\
\hline LBTB & 242.91 & 73.74 & 0.00 & 35.18 & 94.80 & 176.02 & 232.38 \\
\hline DGAR & 245.57 & 25.78 & 0.00 & 34.78 & 89.81 & 173.02 & 229.96 \\
\hline LSZ & 252.47 & 69.56 & 0.00 & 34.34 & 94.12 & 173.68 & 228.30 \\
\hline KMBO & 266.71 & 58.87 & 0.00 & 33.48 & 90.24 & 171.09 & 218.50 \\
\hline MBAR & 267.84 & 65.33 & 0.00 & 34.78 & 91.68 & 173.35 & 220.43 \\
\hline FURI & 278.42 & 57.19 & 0.00 & 34.78 & 88.81 & 167.52 & 215.46 \\
\hline TAM & 292.64 & 89.16 & 0.00 & 33.56 & 90.03 & 173.31 & 225.97 \\
\hline RAYN & 297.13 & 52.71 & 0.00 & 31.11 & 85.20 & 162.84 & 208.45 \\
\hline EIL & 301.12 & 63.32 & 0.00 & 32.14 & 88.42 & 166.53 & 214.23 \\
\hline TIP & 309.15 & 79.57 & 0.00 & 31.70 & 87.51 & 167.56 & 216.47 \\
\hline ANTO & 311.96 & 67.48 & 0.00 & 32.11 & 87.82 & 169.40 & 217.77 \\
\hline GNI & 315.76 & 58.95 & 0.00 & 31.78 & 87.14 & 167.09 & 211.84 \\
\hline TIRR & 315.82 & 71.78 & 0.00 & 32.01 & 87.82 & 167.71 & 218.11 \\
\hline PSZ & 318.17 & 78.25 & 0.00 & 32.59 & 88.30 & 169.39 & 215.48 \\
\hline SUW & 324.69 & 77.27 & 0.00 & 32.12 & 87.81 & 167.04 & 213.46 \\
\hline $\mathrm{OBN}$ & 328.29 & 70.21 & 0.00 & 31.87 & 87.81 & 166.38 & 213.52 \\
\hline VSU & 329.63 & 76.44 & 0.00 & 32.22 & 89.06 & 168.63 & 216.66 \\
\hline
\end{tabular}


Table 6 (continued)

Distribution of the seismic stations and measured time of common pulses for the Sumatra, Indonesia giant earthquake $\left(M_{\mathrm{w}}=9.3\right.$; December 26, 2004)

\begin{tabular}{llllllll}
\hline Station name & $\begin{array}{l}\text { Azimuth } \\
(\mathrm{deg})\end{array}$ & $\Delta(\mathrm{deg})$ & \multicolumn{6}{c}{ Time of common pulses used $(\mathrm{s})$} \\
\cline { 4 - 8 } & & & T1 & T2 & T3 & T4 & T5 \\
\hline AKTK & 331.96 & 56.82 & 0.00 & 31.61 & 86.50 & 163.41 & 207.84 \\
KZA & 337.20 & 42.84 & 0.00 & 31.14 & 86.17 & 165.27 & 211.49 \\
ARU & 337.25 & 60.79 & 0.00 & 31.68 & 87.21 & 164.56 & 208.54 \\
MKAR & 346.87 & 44.88 & 0.00 & 32.12 & 86.84 & 163.30 & 210.90 \\
LSA & 350.60 & 26.66 & 0.00 & 31.80 & 87.83 & 166.51 & 210.24 \\
WMQ & 350.85 & 41.02 & 0.00 & 31.29 & 88.11 & 167.36 & 211.81 \\
\hline
\end{tabular}

2. Alaska, USA $\left(M_{\mathrm{w}}=7.8\right.$; November 3,2002$)$

This situation involved 29 seismograms spanning an azimuthal coverage with an average angular interval of $13^{\circ}$; however, a major gap of $33^{\circ}$ north-northwest of the epicenter is present be-

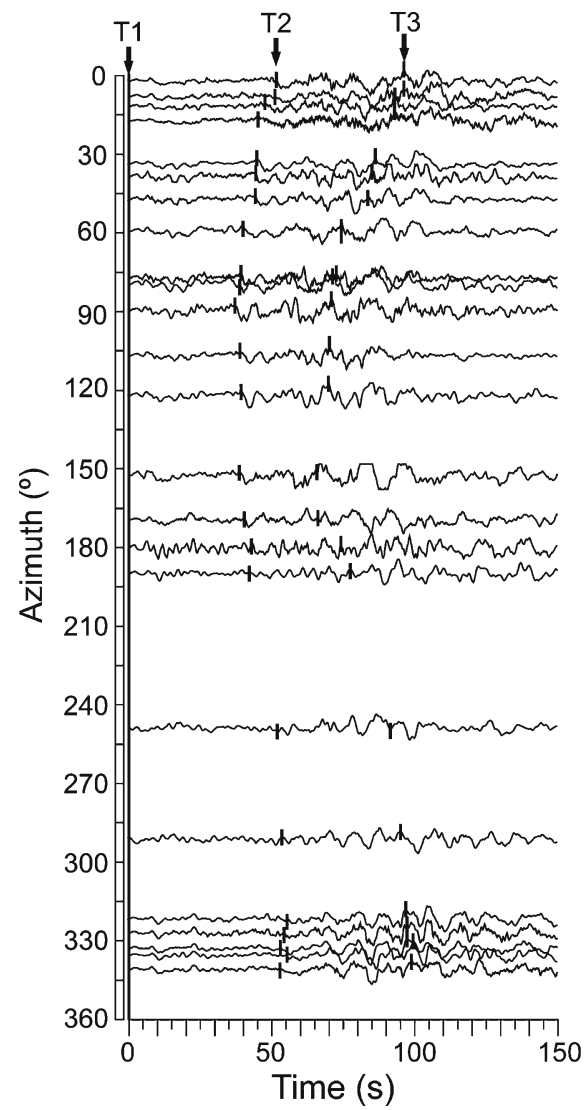

Fig. 15 Vertical P waveforms from the 2001 Arequipa (Peru) earthquake sorted by source-to-station azimuth and aligned at the first-arrived phase (hatched line). The three common pulses (T1, T2, and T3) employed in the directivity method are identified by vertical lines in each seismogram and are listed in Table 3 tween stations BJT and KURK (Table 4). In the selected waveforms represented in Fig. 16, we applied the above criteria and identified two common pulses indicated by $\mathrm{T} 1$ and $\mathrm{T} 2$. It is not possible to identify pulses that are more advanced than T2 ( $\sim 60 \mathrm{~s})$. These pulses were considered to have a reading error of $2.0 \mathrm{~s}$.

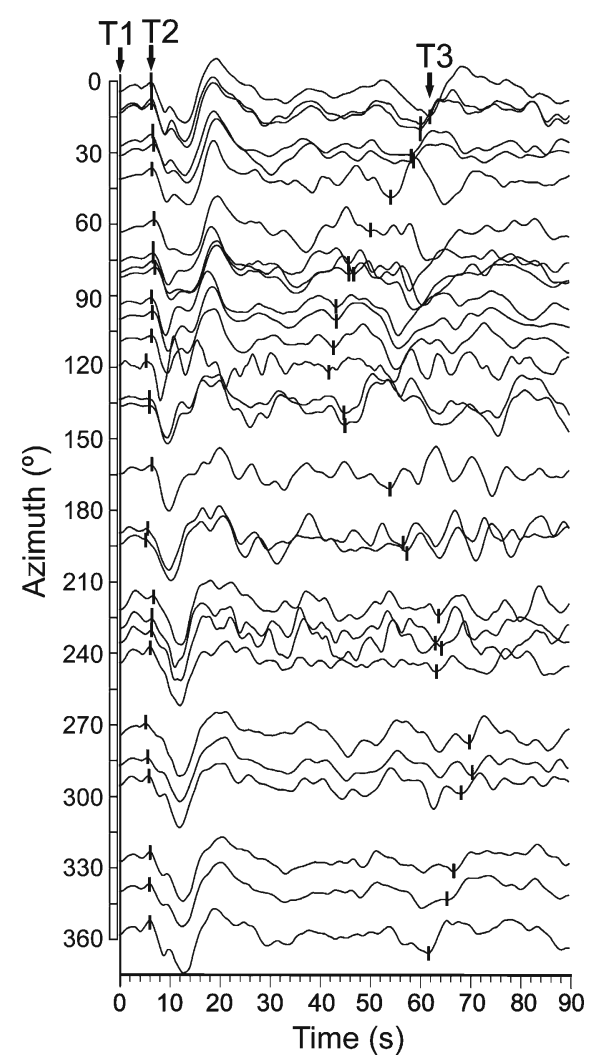

Fig. 16 Vertical $P$ waveforms from the 2002 Denali (AK, USA) earthquake sorted by source-to-station azimuth and aligned at the first-arrived phase (hatched line). The three common pulses (T1, T2, and T3) employed in the directivity method are identified by vertical lines in each seismogram and are listed in Table 4 
3. Zemmouri-Boumerdes, Algeria $\left(M_{\mathrm{w}}=6.8\right.$; May 21, 2003)

Thirty waveforms separated by an average angular interval of $12^{\circ}$ and a major gap of $45^{\circ}$ east of the epicenter, between stations LSA and KMBO, were considered (Table 5). Three common pulses were identified, T1, T2, and T3 (Fig. 17), which explain the rupture during the first $12 \mathrm{~s}$; the pulses were considered to have a reading error of $1.5 \mathrm{~s}$.

4. Sumatra, Indonesia $\left(M_{\mathrm{w}}=9.3\right.$; December 26 , 2004)

For the directivity study of the Sumatra earthquake, 47 waveforms from stations spanning an azimuthal coverage with an average angular interval of $6.7^{\circ}$ and a major gap of $35.36^{\circ}$ southsouthwest of the epicenter, between the AIS and SUR stations (Table 6), were selected. The five pulses selected on the seismograms presented in Fig. 18 follow the rupture propagation during the first $250 \mathrm{~s}$. We estimated the reading errors in the seismograms to be $2.5 \mathrm{~s}$.

Fig. 17 Vertical $P$ waveforms from the 2003 Zemmouri-Boumerdes (Algeria) earthquake sorted by source-tostation azimuth and aligned at the first-arrived phase (hatched line). The three common pulses (T1, T2, and T3) employed in the directivity method are identified by vertical lines in each seismogram and are listed in Table 5

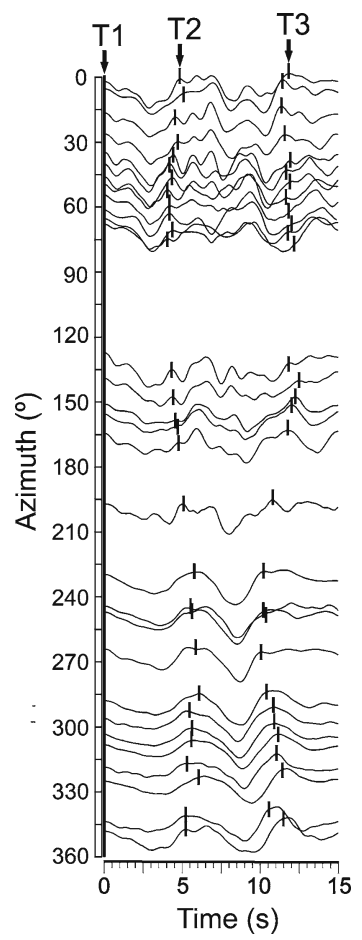

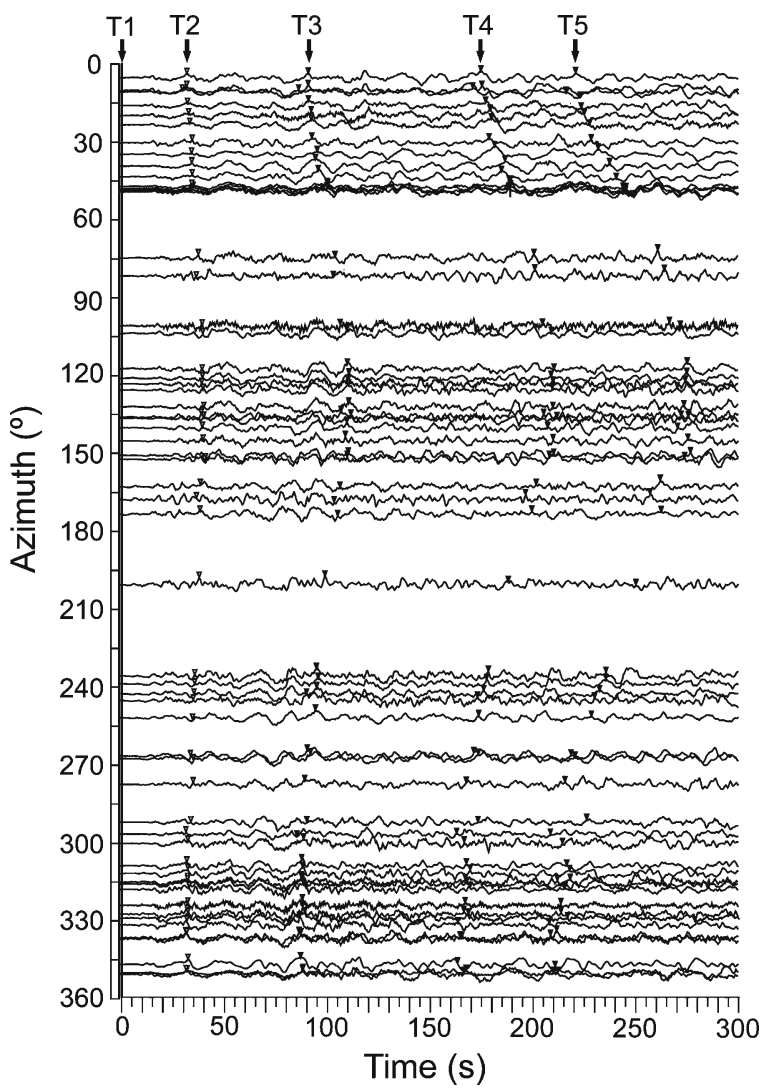

Fig. 18 Vertical $\mathrm{P}$ waveforms from the 2004 Sumatra (Indonesia) earthquake sorted by source-to-station azimuth and aligned at the first-arrived phase (hatched line). For each seismogram, five common pulses (T1, T2, T3, T4, and T5) employed in the DIRDOP method are identified by the inverted triangles. The intervals between the identified pulses, which vary smoothly as a function of azimuth, are listed in Table 6

\subsection{Results}

The results of applying the method to these earthquakes are represented in Figs. 19, 20, 21, 22, 23, and 24 and are listed in Table 7. For the intervals considered ( $\mathrm{D} i ;=1,2,3 \ldots)$, the upper part of Figs. 19-23 shows the azimuthal projection map with the position of each station used and, by isolines, the pulse-time measured in the seismograms, interpolated into each location. The arrows represent the estimated directions for the sections of the rupture. The lower part of Figs. 19-23 shows, as a function of the azimuth from the epicenter, (a) time delays read in seismograms, (b) normalized time delays for an 

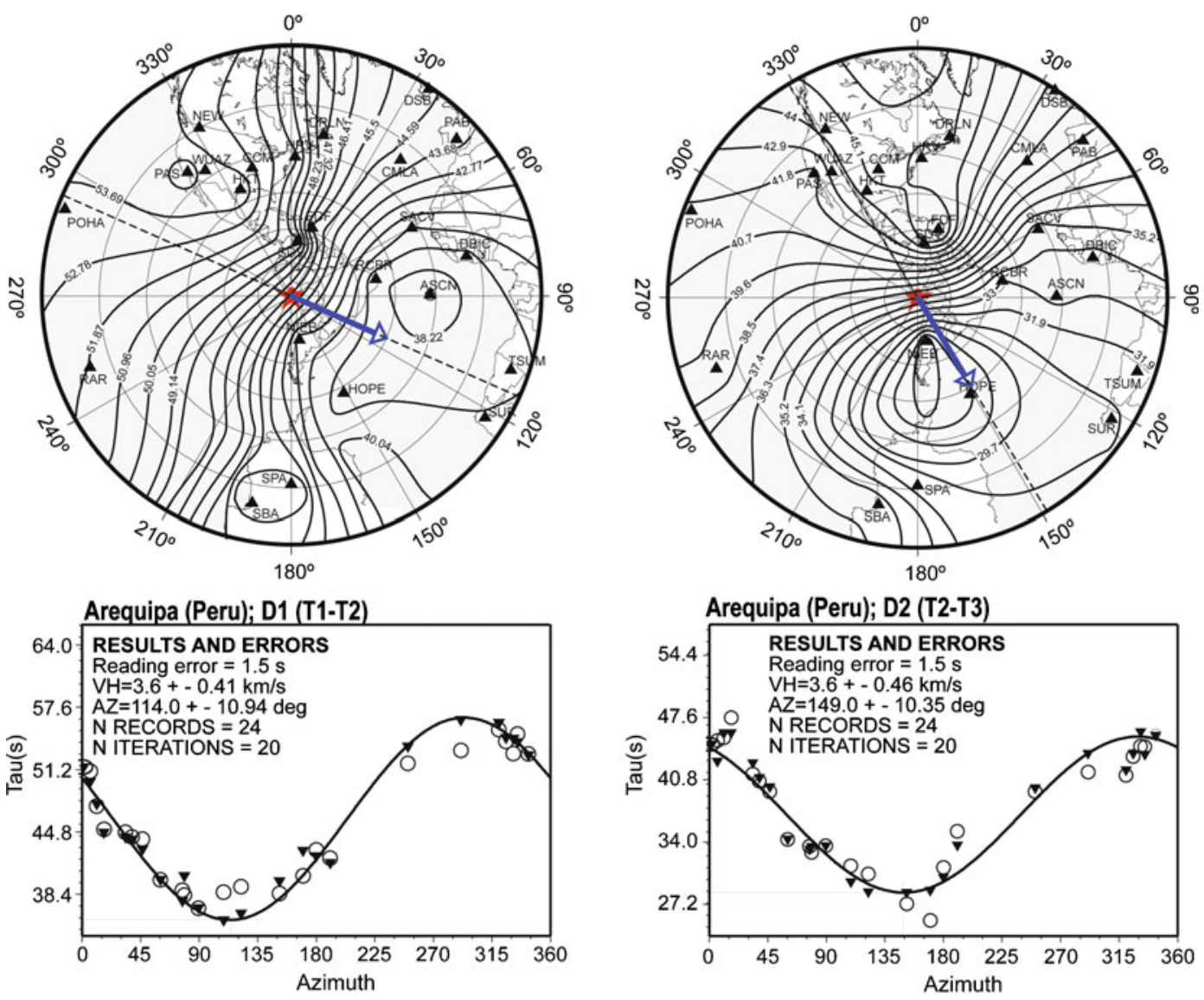

Fig. 19 Directivity results for the Arequipa (Peru) earthquake from the two intervals considered in Fig. 15 and Table 3, D1 (left) and D2 (right). The upper plots show, on an azimuthal projection map centered at the Arequipa earthquake focus, the interpolated spatial distribution (isolines) of the common phase delays. Shaded triangles mark the stations used, and the arrows mark the calculated rupture direction. The lower plots show the phase delay versus azimuth for the intervals D1 and D2. Open circles

epicentral distance, and (c) the fit to the normalized times obtained by DIRDOP. The numerical results that correspond to the fits of Figs. 1923 are shown in Table 7. Finally, we are able to easily compare our results, for each case study, with those obtained previously by other authors (Table 7):

1. Arequipa, Peru $\left(M_{\mathrm{w}}=8.4\right.$; June 23,2001$)$

For the Arequipa earthquake, the initial rupture (first $50 \mathrm{~s})$ occurs toward the $\operatorname{ESE}(\gamma=114.0 \pm$ $11.0^{\circ}$, segment D1) and a second segment of the

and solid inverted triangles represent the time between common pulses measured in seismograms and the corresponding normalized times (for fixed epicentral distance $66.8^{\circ}$ ), respectively. The solid line represents the predicted time delay distribution, which was obtained by inverting the directivity model. The highest correlation coefficient occurs at an azimuth of $114^{\circ}$ (minimum of the curve) for interval D1 and $149^{\circ}$ for interval D2. The corresponding results are listed in Table 7

rupture (next $\sim 30 \mathrm{~s})$ turns toward the $\mathrm{S}(\gamma=$ $149.0 \pm 10.4^{\circ}$, segment D2). The rupture velocity in both segments is $3.6 \mathrm{~km} / \mathrm{s}$ (Fig. 19). From these results, it is possible to explain the first $82 \mathrm{~s}$ of the rupture, which corresponds to about $295 \mathrm{~km}$ of the fault. These results, similar to those obtained with different methods in other studies, suggest that the rupture occurred on plane A of the focal mechanism represented in Fig. 14. Bilek and Ruff (2002) analyzed the relative source time function durations obtained from surface wave data and found a rupture azimuth of $\gamma=116^{\circ}$. 

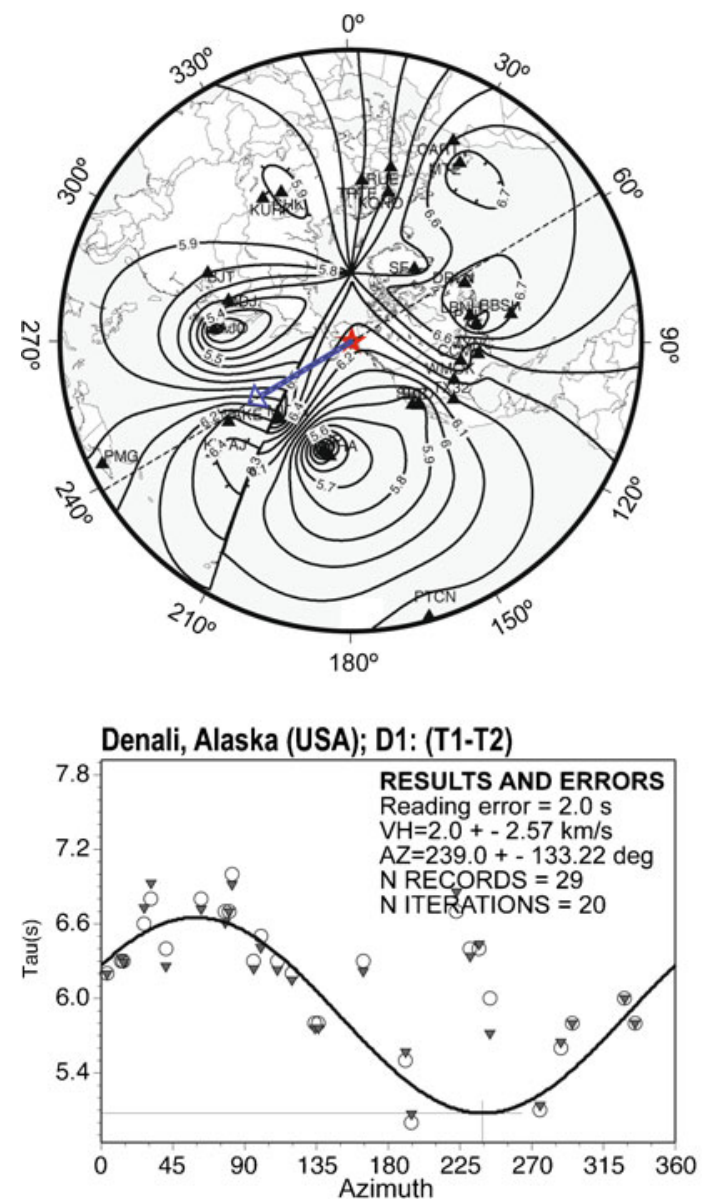

Fig. 20 Directivity results for the Denali (AK, USA) earthquake from the two intervals shown in Fig. 16 and listed in Table 4. The upper plots show, on an azimuthal projection map centered at the Denali (AK, USA) earthquake focus, the interpolated spatial distribution (isolines) of the common phase delays. Shaded triangles mark the stations used, and arrow marks the calculated rupture direction. The lower plots show the phase delay versus azimuth for the D1 intervals. Open circles and solid inverted

Robinson et al. (2006), applying the linear programming method of Das and Kostrov (1990), showed a unilateral rupture that propagated from northwest to southeast with an average rupture velocity of $3.5 \mathrm{~km} / \mathrm{s}$, corresponding with the result obtained by DIRDOP $(3.6 \mathrm{~km} / \mathrm{s})$. The results of Le Pichon et al. (2002) obtained by analysis of the ground-coupled air waves show that the rupture propagated southeast at a rupture velocity of $3.3 \pm 0.3 \mathrm{~km} / \mathrm{s}$ with a source duration of $90 \pm 10 \mathrm{~s}$. Pritchard et al. (2007) determined the spatiotem-
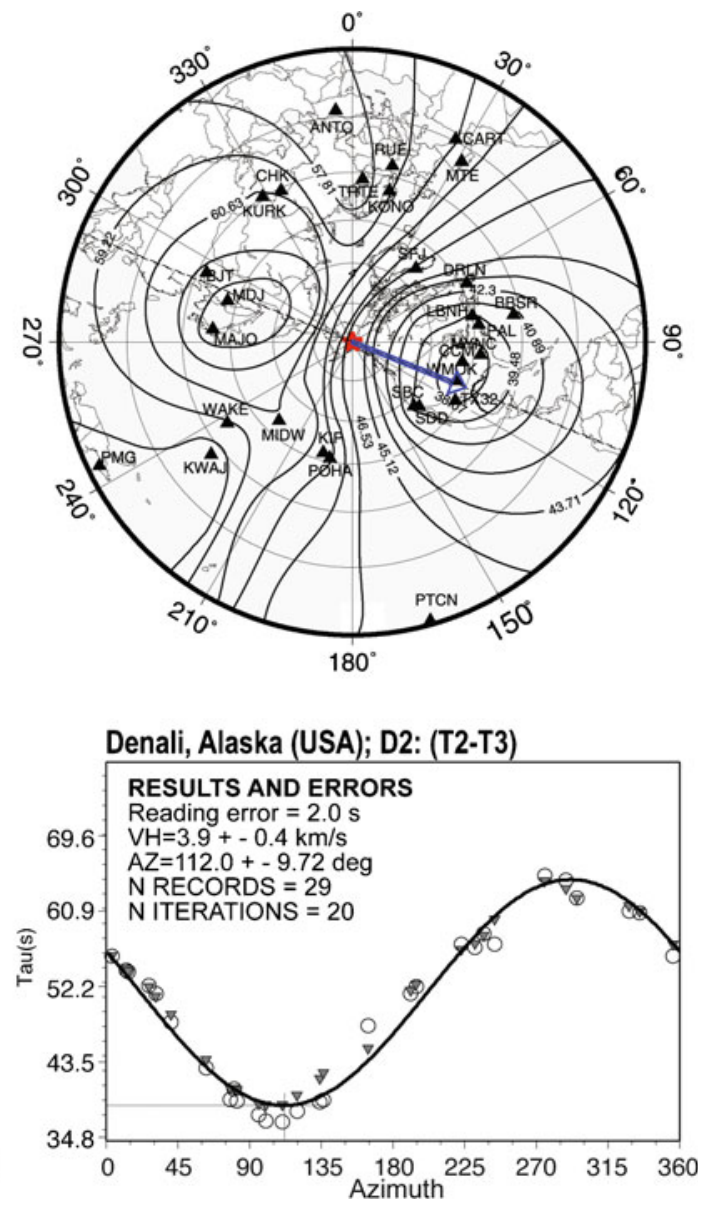

triangles represent the time between common pulses measured in seismograms and the related normalized times (for the fixed epicentral distance), respectively. The solid line represents the predicted time delay distribution, which was obtained by inverting the directivity model. The highest correlation coefficient occurs at an azimuth of $239^{\circ}$ (minimum of the curve) for interval D1 and $112^{\circ}$ for interval D2. The corresponding results are listed in Table 7

poral slip distribution using a joint inversion of teleseismic, geodetic, and strong-motion data, and two average rupture directions can be seen, as in the DIRDOP results, although with slightly different azimuths. From the Pritchard slip distribution, the azimuth of the two segments of rupture are $\gamma 1=127^{\circ}$ and $\gamma 2=176^{\circ}$; DIRDOP method gives $\gamma 1=114.0 \pm 10.94$ and $\gamma 2=149.0 \pm 10.35$. In the work of Pritchard et al. (2007), they obtained an average rupture velocity value of $2.7 \mathrm{~km} / \mathrm{s}$. 

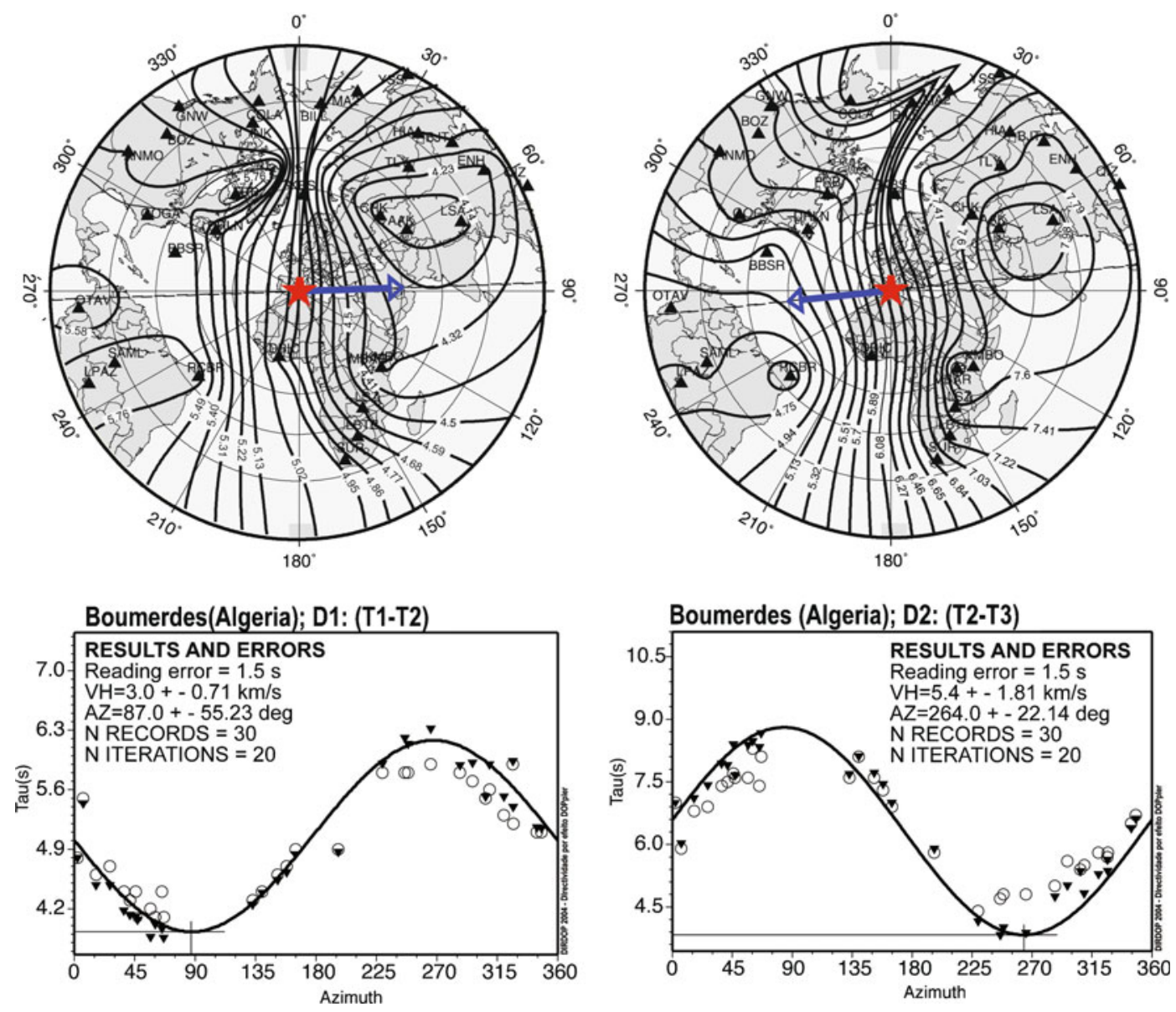

Fig. 21 Directivity results for the Zemmouri-Boumerdes (Algeria) earthquake from the two intervals considered in Fig. 17 and Table 5, D1 (left) and D2 (right). The upper plots show, on an azimuthal projection map centered at the Zemmouri-Boumerdes (Algeria) earthquake focus, the interpolated spatial distribution (isolines) of the common phase delays. Shaded triangles mark the stations used, and the arrow marks the calculated rupture direction. The lower plots show the phase delay versus azimuth for the D1

The direction and length of the D1 and D2 segments, estimated from the times used and respective rupture velocity found, are projected on the map of Fig. 24a, which also shows the slip distribution detected by Pritchard et al. (2007). Table 7 compares all these values.

2. Denali, AK, USA $\left(M_{\mathrm{w}}=7.8\right.$; November 3 , 2002)

For the Denali (AK, USA) earthquake, the results that correspond to the sections of break that

and D2 intervals. Open circles and solid inverted triangles represent the time between common pulses measured in seismograms and the related normalized times (for fixed epicentral distance), respectively. The solid line represents the predicted time delay distribution, which was obtained by inverting the directivity model. The highest correlation coefficient occurs at an azimuth of $87^{\circ}$ (minimum of the curve) for interval D1 and $264^{\circ}$ for interval D2. The corresponding results are listed in Table 7

occurred in the intervals $\sim 0-5$ and $\sim 5-55 \mathrm{~s}$ are represented in Fig. 20 and Table 7. These intervals correspond mainly to the first and second sections of the rupture along the Susitna Glacier fault and Denali fault, as observed in other studies (e.g., Eberhart-Phillips et al. 2003; Ozacar and Beck 2004). The results showed that the first $\sim 5 \mathrm{~s}$ (D1) are derived from a dataset that does not produce a good fit to the theoretical model (Fig. 20). Consequently, high values of error were found in both the rupture velocity $(2.0 \pm 2.57 \mathrm{~km} / \mathrm{s})$ and the 

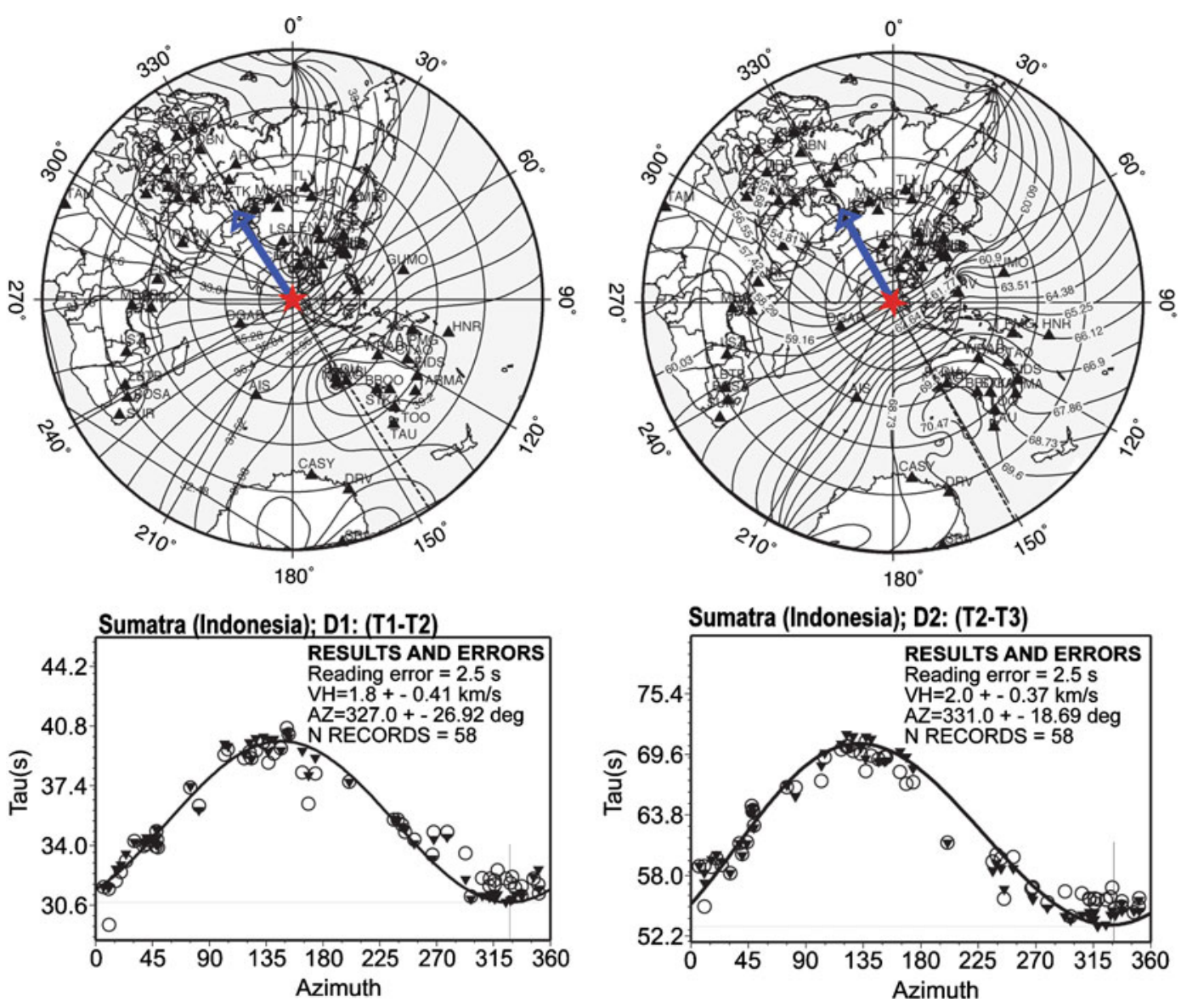

Fig. 22 Directivity results for the Sumatra (Indonesia) earthquake from the two first of four intervals considered in Fig. 18 and Table 6, D1 (left) and D2 (right). The upper plots show, on an azimuthal projection map centered at the Sumatra (Indonesia) earthquake focus, the interpolated spatial distribution (isolines) of common phase delays. Shaded triangles mark the stations used, and the arrow marks the calculated rupture direction. The lower plots show the phase delay versus azimuth for the D1 and D2

direction $(\gamma=239.0 \pm 2.57 \mathrm{~km} / \mathrm{s})$. As discussed above (results of the synthetic $\mathrm{C} 2$ ), this behavior suggests that the section of the rupture that corresponds to the first $5 \mathrm{~s}$ is bilateral. This conclusion is consistent with the models presented by Eberhart-Phillips et al. (2003) or Dunham and Archuleta (2004), who describe this rupture with emerging bilateral to unilateral change after the first few seconds. The next $\sim 50 \mathrm{~s}$ shows a unilateral rupture, with a length estimated to be $273 \mathrm{~km}$ toward the ESE with an azimuth of $\gamma=112 \pm$ $7.27^{\circ}$. This suggests that the rupture corresponds

intervals. Open circles and solid inverted triangles represent the time between common pulses measured in seismograms and the related normalized times (for the fixed epicentral distance), respectively. The solid line represents the predicted time delay distribution, which was obtained by inverting the directivity model. The highest correlation coefficient occurs at an azimuth of $327^{\circ}$ (minimum of the curve) for interval D1 and $331^{\circ}$ for interval D2. The corresponding results are listed in Table 7

to plane A of the focal mechanism represented in Fig. 14 and adjusts with those determined from the teleseismic body waveform inversion (Kikuchi and Yamanaka 2002; Ozacar and Beck 2004) or strong-motion waveforms (Eberhart-Phillips et al. 2003; Frankel 2004). An average rupture velocity of $3.9 \mathrm{~km} / \mathrm{s}$ was found in this study that can be compared with the $3.5 \mathrm{~km} / \mathrm{s}$ determined from the inversion of strong-motion waveforms by Frankel (2004) and Eberhart-Phillips et al. (2003). Velasco et al. (2004), who investigated the directivity of this earthquake by analyzing the 

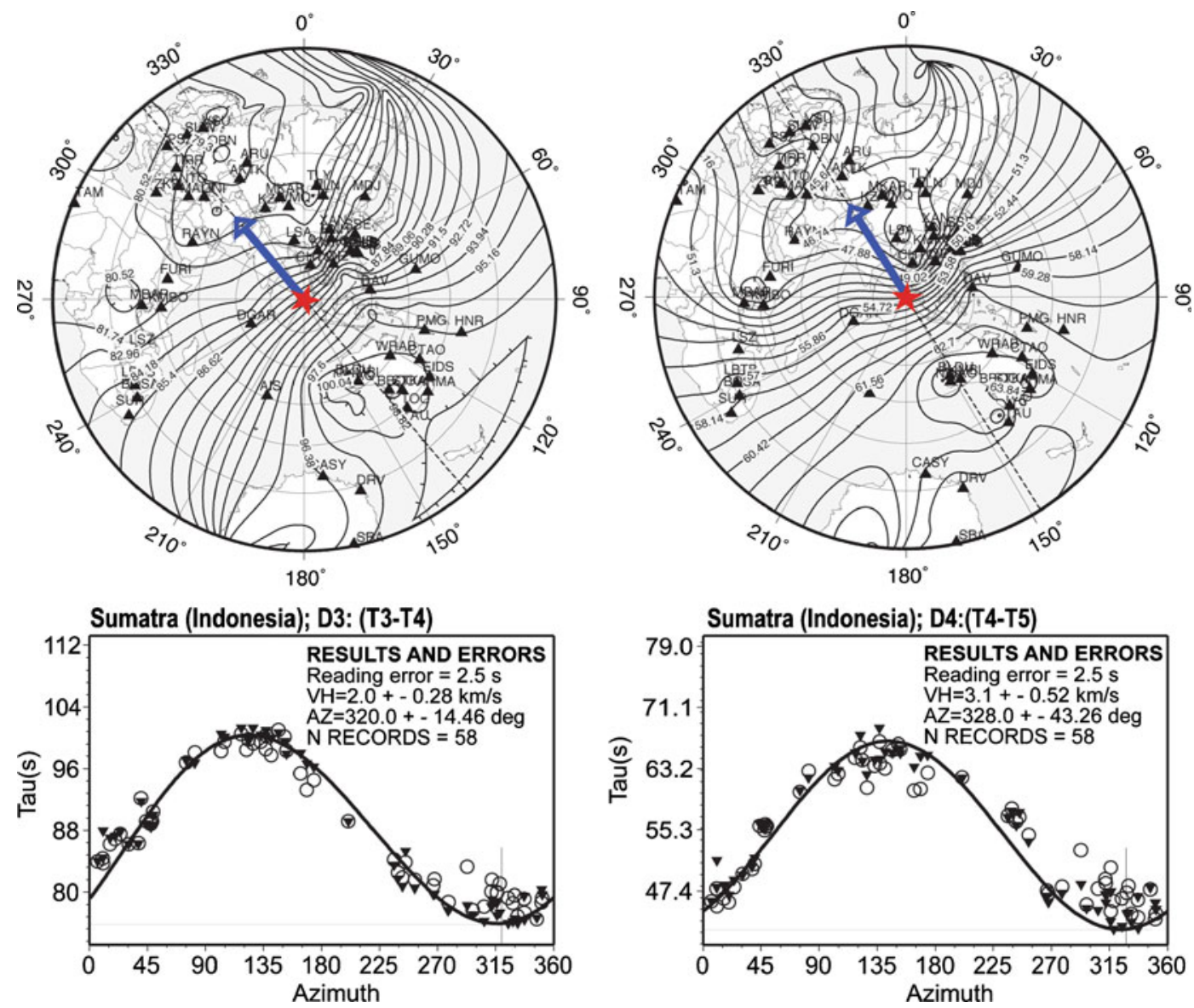

Fig. 23 Directivity results for the Sumatra (Indonesia) earthquake from the two last of four intervals considered in Fig. 18 and Table 6, D3 (left) and D4 (right). The upper plots show, on an azimuthal projection map centered at the Sumatra (Indonesia) earthquake focus, the interpolated spatial distribution (isolines) of common phase delays. Shaded triangles mark the stations used, and the arrow marks the calculated rupture direction. The lower plots show the phase delay versus azimuth for the D3

surface wave-amplitude and pulse-width variations of the relative source time functions calculated by the empirical Green functions method, found $\gamma=122 \pm 25^{\circ}$ and a rupture velocity of $3.2 \mathrm{~km} / \mathrm{s}$. Liao and Huang (2008), using the inversion of the empirical Green's function, found a unilateral source rupture with a total duration $74 \mathrm{~s}$ and a rupture velocity with a maximum of $3.32 \mathrm{~km} / \mathrm{s}$ and a minimum of $2.64 \mathrm{~km} / \mathrm{s}$ (the average rupture velocity was about $2.95 \mathrm{~km} / \mathrm{s}$ ). The azimuth of the rupture was approximately $130^{\circ}$.

and D4 intervals. Open circles and solid inverted triangles represent the time between common pulses measured in seismograms and the related normalized times (for fixed epicentral distance), respectively. The solid line represents the predicted time delay distribution, which was obtained by inverting the directivity model. The highest correlation coefficient occurs at an azimuth of $320^{\circ}$ (minimum of the curve) for interval D3 and $328^{\circ}$ for interval D4. The corresponding results are listed in Table 7

A comparison with the other studies is laid out in Table 7. The direction of the rupture and the respective length, estimated from the time interval and rupture velocity, are shown in Fig. 24b, which overlap the slip distribution proposed by Ozacar and Beck (2004).

3. Zemmouri-Boumerdes, Algeria $\left(M_{\mathrm{w}}=6.8\right.$; May 21, 2003)

In the case of the Zemmouri-Boumerdes (Algeria) earthquake, the results show a bilateral rupture in the E-W direction (Fig. 21) and suggest 
Fig. 24 Summary of the front expansion for the four studied earthquakes inferred from the directivity results listed in Table 7: a the Arequipa (Peru) earthquake, b the Denali (AK, USA) earthquake, c the Zemmouri-Boumerdes (Algeria) earthquake, and $\mathbf{d}$ the Sumatra (Indonesia) earthquake. The red star marks the epicenter, and the black arrows represent the average direction and the extent of the rupture front during the related period. For each situation, the results of DIRDOP are compared with significant results published by the authors referenced

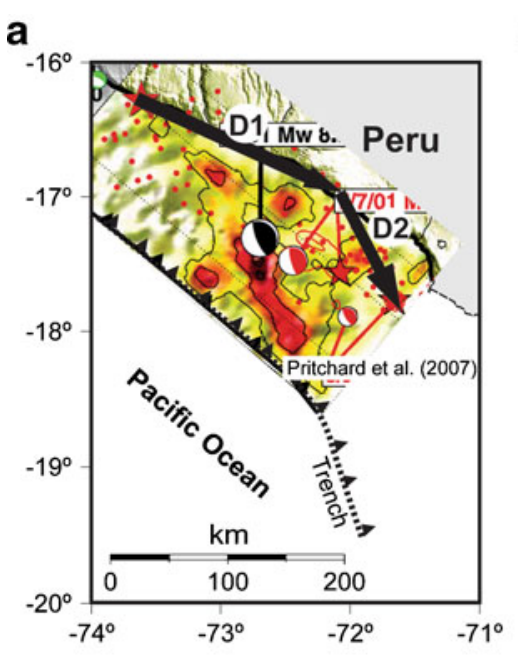

b

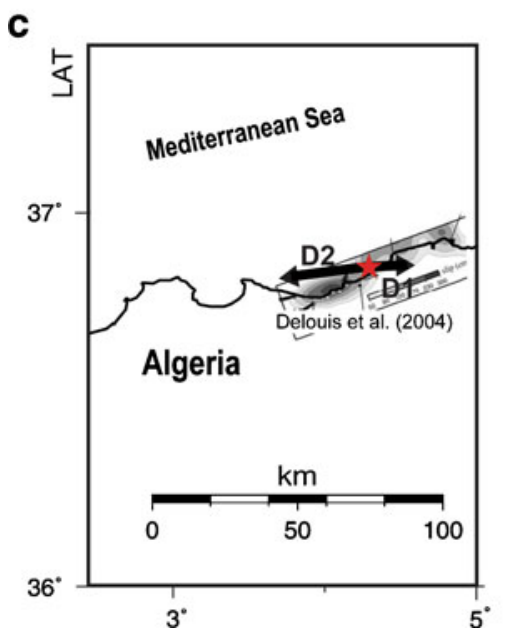

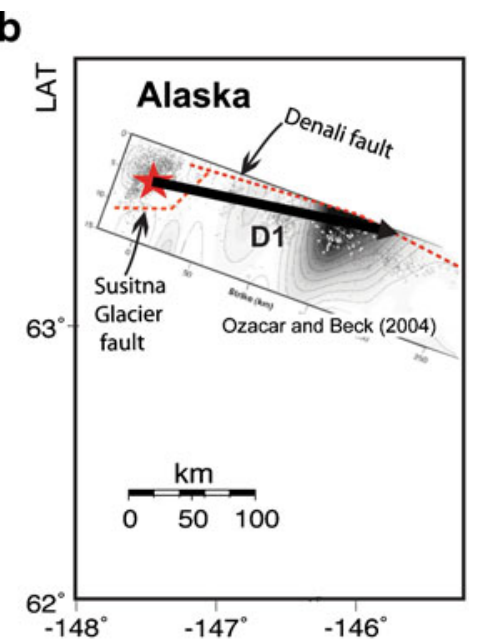

d

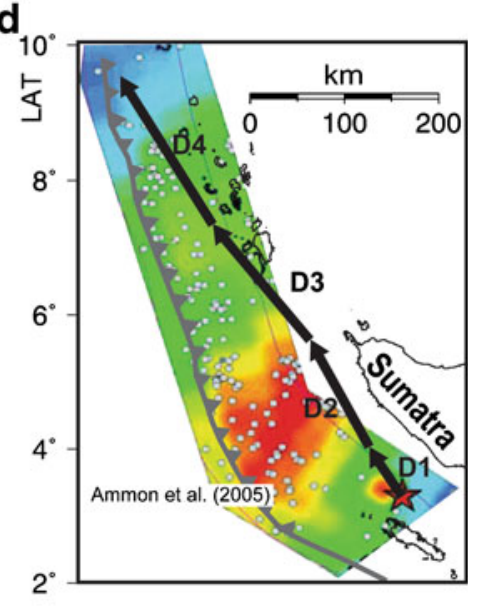

that the rupture corresponds to plane A of the focal mechanism represented in Fig. 14. In the first $5 \mathrm{~s}$ (segment D1), the rupture propagates from the epicenter toward the east $\left(\gamma=87.0 \pm 55.23^{\circ}\right)$ at an average velocity of $3.0 \pm 0.71 \mathrm{~km} / \mathrm{s}$. In the last $10 \mathrm{~s}$, the rupture propagates at an average velocity of $5.4 \pm 1.81 \mathrm{~km} / \mathrm{s}$ but in the opposite direction $\left(\gamma=264 \pm 22^{\circ}\right.$; segment D2). The bilaterality of the rupture was also reported by Yagi (2003), Delouis et al. (2004), Semmane et al. (2005), and Belabbès et al. (2009). Yagi (2003) found an asymmetric bilateral rupture that mainly propagated $30 \mathrm{~km}$ to the southwest and $20 \mathrm{~km}$ to the northeast. Delouis et al. (2004), by joint inversion of teleseismic waveforms and global positioning system (GPS) data, estimate two slip zones, on both sides (NE and SW) of the hypocenter, and low rupture velocity $(2.4 \mathrm{~km} / \mathrm{s}$ in $\mathrm{NE}$ section and $1.9 \mathrm{~km} / \mathrm{s}$ in $\mathrm{SW}$ section). Semmane et al. (2005), using an inversion analysis of strong-motion and GPS data, fixed the fault orientation (USGS CMT), and the slip distribution result also reveals the two patches of a bilateral rupture. Belabbès et al. (2009) studied the surface deformation associated with the May 21, 2003 Zemmouri (Algeria) earthquake by inversion of InSAR, coastal uplift, and GPS data and found two rupture sections on both sides of the epicenter. The direction of each segment and the respective length, estimated from the time interval and rupture velocity, are shown in Table 7 and Fig. 24c which also shows, in overlap, the slip distribution calculated by Delouis et al. (2004). 
Table 7 Summary of results

\begin{tabular}{|c|c|c|c|c|}
\hline Event & Section considered & $\begin{array}{l}\text { Rupture azimuth } \\
\text { (deg) }\end{array}$ & $\begin{array}{l}\text { Rupture velocity } \\
(\mathrm{km} / \mathrm{s})\end{array}$ & Authors \\
\hline \multirow{7}{*}{$\begin{array}{l}\text { Arequipa (Peru) } \\
2001\end{array}$} & D1 (0-50 s) & $114.0 \pm 10.94$ & $3.6 \pm 0.41$ & This work \\
\hline & D2 (50-82 s) & $149.0 \pm 10.35$ & $3.6 \pm 0.46$ & \\
\hline & All rupture & 116 & - & Bilek and Ruff (2002) \\
\hline & All rupture & - & 3.5 & Robinson et al. (2006) \\
\hline & $0-50 \mathrm{~s}$ & $127^{\mathrm{a}}$ & 2.7 & Pritchard et al. (2007) \\
\hline & $50-80 \mathrm{~s}$ & $176^{\mathrm{a}}$ & & \\
\hline & All rupture $(\sim 90 \mathrm{~s})$ & - & $3.3 \pm 0.3$ & Le Pichon et al. (2002) \\
\hline \multirow{12}{*}{$\begin{array}{l}\text { Denali (AK, USA) } \\
2002\end{array}$} & D1 $(0-5 s)$ & $239.0 \pm 133.2$ & $2.0 \pm 2.57$ & This work \\
\hline & D2 (5-55 s) & $112.0 \pm 7.27$ & $3.9 \pm 0.4$ & \\
\hline & All rupture & $122.0 \pm 25$ & 3.2 & Velasco et al. (2004) \\
\hline & & - & 3.5 & Frankel (2004) \\
\hline & $\sim 0-20 \mathrm{~s}$ & 90 & 3.2 & Ozacar and Beck (2004) \\
\hline & $\sim 20-120 \mathrm{~s}$ & 110 & & \\
\hline & Along Susitna Glacier f & ult $(\sim 40 \mathrm{~km})$ & 3.5 & Eberhart-Phillips et al. (2003) \\
\hline & Along Denali fault $(\sim 20$ & $\mathrm{km})$ & & \\
\hline & Along Totschunda fault & $(\sim 60 \mathrm{~km})$ & & \\
\hline & First $30 \mathrm{~s}$ & 47 & 3 & Kikuchi and Yamanaka (2002) \\
\hline & Last $70 \mathrm{~s}$ & 114 & & \\
\hline & All rupture (74 s) & 130 & 2.95 & Liao and Huang (2008) \\
\hline \multirow{10}{*}{$\begin{array}{l}\text { Zemmouri-Boumerdes } \\
\text { (Algeria) } 2003\end{array}$} & D1 $(0-5 s)$ & $87.0 \pm 55.23$ & $3.0 \pm 0.71$ & This work \\
\hline & D2 (5-10 s) & $264.0 \pm 22.0$ & $5.40 \pm 1.81$ & \\
\hline & $30 \mathrm{~km}$ & SW & - & Yagi (2003) \\
\hline & $20 \mathrm{~km}$ & $\mathrm{NE}$ & - & \\
\hline & $30 \mathrm{~km}$ & 70 & $2.0-2.4$ & Delouis et al. (2004) \\
\hline & $24 \mathrm{~km}$ & 250 & $1.6-1.9$ & \\
\hline & $38 \mathrm{~km}$ & 58 & 2.8 & Semmane et al. (2005) \\
\hline & $26 \mathrm{~km}$ & 238 & & \\
\hline & $\sim 30 \mathrm{~km}$ & 65 & - & Belabbès et al. (2009) \\
\hline & $\sim 30 \mathrm{~km}$ & 245 & - & \\
\hline \multirow{17}{*}{$\begin{array}{l}\text { Sumatra (Indonesia) } \\
2004\end{array}$} & D1 (0-35 s) & $327.0 \pm 16.92$ & $1.8 \pm 0.31$ & This work \\
\hline & D2 (35-100 s) & $331.0 \pm 8.69$ & $2.0 \pm 0.17$ & \\
\hline & D3 (100-180 s) & $320.0 \pm 5.98$ & $2.0 \pm 0.11$ & \\
\hline & D4 (180-240 s) & $328.0 \pm 12.98$ & $3.1 \pm 0.18$ & \\
\hline & $0-60 \mathrm{~s}$ & $\begin{array}{l}\text { Parallel to trench } \\
\text { direction }\end{array}$ & $1.7-2.2$ & $\begin{array}{l}\text { Krüger and Ohrnbergers } \\
(2005 b)\end{array}$ \\
\hline & $60 \mathrm{~s}-$ final & & $2.5-3.5$ & \\
\hline & All rupture & $310-330^{\circ}$ & 2.5 & Ammon et al. (2005) \\
\hline & $0-60 \mathrm{~s}$ & & $\sim 1.3$ & \\
\hline & 60 s-final & & $\sim 3.0$ & \\
\hline & All rupture (550 s) & - & 2.3 & Lambotte et al. (2007) \\
\hline & All rupture & $\begin{array}{l}\text { Parallel to trench } \\
\text { direction }\end{array}$ & $2.0-3.0$ & Lay et al. (2005) \\
\hline & All rupture $(8 \mathrm{~min})$ & Aftershock zone & 2.8 & Ishii et al. (2005) \\
\hline & All rupture & $\begin{array}{l}\text { Parallel to trench } \\
\text { direction }\end{array}$ & $1.8-2.8$ & Rhie et al. (2007) \\
\hline & All rupture $(1,200 \mathrm{~km})$ & $\begin{array}{l}\text { Parallel to trench } \\
\text { direction }\end{array}$ & $2.2 \pm 0.1$ & Vallée (2007) \\
\hline & First $100 \mathrm{~km}$ & & 1.8 & \\
\hline & $100-500 \mathrm{~km}$ & & $2.4-2.5$ & \\
\hline & $500 \mathrm{~km}$-final & & 2 & \\
\hline
\end{tabular}

Summary of the direction and velocity of the rupture and errors obtained in this work corresponding to each considered time interval of each earthquake studied and the same parameters calculated by other authors

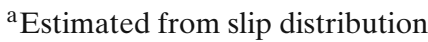


4. Sumatra, Indonesia $\left(M_{\mathrm{w}}=9.3\right.$; December 26 , 2004)

In the case of the Sumatra mega-earthquake, the results corresponding to the fits shown in Figs. 22 and 23 are represented in Table 7 . These results suggest that the rupture corresponds to plane A of the focal mechanism represented in Fig. 14 and shows that (1) the rupture started slowly $\left(v_{\mathrm{r}}=\right.$ $1.8 \pm 0.11 \mathrm{~km} / \mathrm{s}$ ) in the first $35 \mathrm{~s}$ (segment D1), occurring mainly toward the $\mathrm{NW}, \gamma=327 \pm 26.9^{\circ}$ direction; the low value obtained for the rupture velocity in this interval suggests a bilateral circular rupture that corresponds to the nucleation; (2) during 35 to $100 \mathrm{~s}$ (segment D2), the rupture propagates in the $\gamma=331 \pm 18.7^{\circ}$ direction with a moderate rupture velocity $\left(v_{\mathrm{r}}=2.0 \pm 0.37 \mathrm{~km} / \mathrm{s}\right)$; (3) in the third time interval, between 100-180 s (segment D3), the rupture expands in the $\gamma=$ $320 \pm 14.4^{\circ}$ direction with a $v_{\mathrm{r}}=2.0 \pm 0.28 \mathrm{~km} / \mathrm{s}$; and (4) finally, in the last interval analyzed by this method, 180-240 s (segment D4), the rupture continues expanding in the north-northwest direction $\left(\gamma=328 \pm 43.26^{\circ}\right)$ but exhibits a higher velocity $\left(v_{\mathrm{r}}=3.1 \pm 0.52 \mathrm{~km} / \mathrm{s}\right)$. The direction of each segment and the correspondent rupture velocity are shown in Table 7. By way of the directivity results, it is possible to explain only the first $240 \mathrm{~s}$ of the rupture, which correspond to about $540 \mathrm{~km}$ of length. It was impossible to identify common pulses after this time due to the interference of later-arriving seismic waves reflected from the surface and discontinuities in the Earth, with $\mathrm{P}$ waves radiating from later portions of the rupture. This limitation of the study of large earthquakes is common in methods that involve the analysis of extended portions of seismic body waveforms. Details of the rupture velocity show that the propagation is much slower in the first stage of the rupture process (first $60 \mathrm{~s}$ ) and accelerates to $3.1 \mathrm{~km} / \mathrm{s}$ from that point onward. The very slow velocity during the first $60 \mathrm{~s}(1.8 \mathrm{~km} / \mathrm{s})$ may be associated with the bilateral or circular character of the first phase of the rupture. The direction of each segment and the respective length estimated from the time interval and rupture velocity are shown in Fig. 24c, which also shows the slip distribution detected by Ammon et al. (2005).
Similar results, listed in Table 7, were obtained by other authors. Krüger and Ohrnberger (2005b) show that the rupture started rather slowly for the first $60 \mathrm{~s}$ (average rupture velocity between 1.7 and $2.2 \mathrm{~km} / \mathrm{s}$ ) and then accelerated to a more constant level between 2.5 and $3.5 \mathrm{~km} / \mathrm{s}$. Ammon et al. (2005) proposed an average rupture velocity of $2.5 \mathrm{~km} / \mathrm{s}$ along a rupture direction of $310^{\circ}$ to $330^{\circ}$. Lambotte et al. (2007) deduced an average rupture velocity of about $2.3 \pm 0.3 \mathrm{~km} / \mathrm{s}$ from the spatiotemporal results (length of approximately $1,250 \mathrm{~km}$ and duration of approximately $550 \mathrm{~s}$ ). Lay et al. (2005) found the variable velocity to be between 2.0 and $3.0 \mathrm{~km} / \mathrm{s}$. Ishii et al. (2005) mapped the rupture spread northward at a velocity of roughly $2.8 \mathrm{~km} / \mathrm{s}$ for approximately $8 \mathrm{~min}$. Rhie et al. (2007) determined rupture velocities between 1.8 and $2.8 \mathrm{~km} / \mathrm{s}$. Vallée (2007) found an average rupture velocity of $2.2 \mathrm{~km} / \mathrm{s}( \pm 0.1)$ that was unequally distributed throughout three sections: (1) the first $100 \mathrm{~km}$ with $\sim 1.8 \mathrm{~km} / \mathrm{s}$, (2) accelerating to values of $2.4-2.5 \mathrm{~km} / \mathrm{s}$ for the next $500 \mathrm{~km}$, and (3) decelerating to $2 \mathrm{~km} / \mathrm{s}$ in the second half of the rupture process.

\section{Discussion and conclusions}

The purpose of the seismic source investigation is to obtain an accurate description of the rupture from seismic data. Geodesic records can sometimes facilitate this process. The success of this depends fundamentally on three factors: source models, informative content of the data, and the methods used. Currently, seismic wave inversion techniques are considered better methods for obtaining rupture characteristics from seismic data. This is a delicate problem because of the number of parameters needed for estimation and the nonlinear setting in which the problem develops. The accuracy of the inversion solutions depends largely on the correct choice of the free and fixed parameters of the method; if the fixed parameters are few and their values are adequately chosen (guided by other methods and data), the process of obtaining the solution can be controlled substantially. The evaluation of directions and velocities for seismic ruptures is an important problem 
in the field of the finite seismic source. We note that even when rupture velocity values are calculated, their corresponding directions generally remain undetermined. They are fixed by considerations of the geometry of faults or by considering one of the planes of the focal mechanism. The approach described provides a tool that, using Doppler interpretation, allows for the estimation of the rupture vector velocity. The ability to determine these parameters from a simple analysis of the seismic data is a very useful outcome of this method because these parameters are difficult to calculate using other methods. Sometimes the velocities of rupture are simply fixed in the accepted band (2.4-3.6 km/s). However, theoretical studies (e.g., Day 1982) reveal the possibility of a wider band. In fact, in the Izmith (Turkey) earthquake of 1999, rupture velocities of $5.8 \mathrm{~km} / \mathrm{s}$ (Sekiguchi and Iwata 2002) and $4.8 \mathrm{~km} / \mathrm{s}$ (Bouchon et al. 2002) were detected.

The methodology presented here can use data obtained directly by identifying common pulses in the azimuthal distributions of seismograms, as well as data obtained from other sources of rupture information. Two of these other sources are the RSTF and the body waves amplitude spectra diagrams. In RSTF, the intervals between common marks are used, whereas in the spectra diagrams, we use corner frequencies. The quality of the results depends on the accuracy of the phase identification and azimuthal coverage. The estimates of error obtained by this method depend strongly on azimuthal gaps in the data, especially if these gaps coincide with the directions of the extrema of the model (Eq. 6).

This method can be applied to any unilateral earthquake, depending only on whether it is possible to identify common pulses. It can be used for small earthquakes, provided that the following two conditions are met: (a) it is possible to identify common pulses in all seismograms and (b) the measured time-delays are perceptible, i.e., they are at least one order of magnitude greater than the uncertainties. For small events, however, it is difficult to apply the method, mainly for two reasons. First, the seismograms need to be acquired at short distances, where it is not common to have a dense azimuthal coverage. Second, considering the short source time duration of small earthquakes, directivity effects are less clear in the seismograms;

If we consider that the two commonly selected pulses in an azimuthal distribution of waveforms correspond to the two ends of the rupture, the time delay between these two pulses is equal to the apparent source time rupture $\tilde{T}_{0}$. From Eq. 12, we conclude that the maximum difference between relative time durations measured in the records is found for a pair of observation points, where one point is aligned with the rupture direction $(\theta=0)$ and the other lies in the opposite direction $\left(\theta=180^{\circ}\right)$.

$\Delta \tilde{T}_{\max }=\tilde{T}_{0}(180, p)-\tilde{T}_{0}(0, p)=2 L \frac{p}{R_{0}}$

Figure 25 shows the distribution of $\Delta \tilde{T}_{\max }$ as a function of the observation distance and rupture dimension. It also indicates the predicted differences in five moderate and large earthquakes. Let us note, in Fig. 25, that the four earthquakes studied herein are situated above the discriminatory limit. The Boumerdes (Algeria) earthquake is situated close to this limit. In the Arequipa earthquake, for an observation distance of $20^{\circ}, \Delta \tilde{T}_{\max } \approx 50 \mathrm{~s}$ is expected, whereas for $80^{\circ}, \Delta \tilde{T}_{\max }<40$ s. If we suppose that the experimental discriminatory limit between directive and antidirective records is about $3 \mathrm{~s}$, the directivity of events like the Azores earthquake of July 9, $1998\left(M_{\mathrm{w}}=5.8\right)$ can only be studied using data from distances of less than $20^{\circ}$. However, there are rarely enough stations at these short distances to provide good azimuthal coverage. For very large earthquakes (like Sumatra), these restrictions do not apply; however, other factors complicate the extensive use of the methodology. The records of very extensive seismic ruptures from a certain moment will be composed of many phases that arise from various points of rupture. The interference of these phases will eventually erase the common marks being sought, and the methodology cannot be applied. Ten synthetic scenarios of common unilateral and bilateral ruptures were used to test the efficiency of the methodology to estimate the direction and velocity of the rupture under the control of various parameters, such as the focal mechanism, complexity of the rupture, azimuthal coverage, velocity of the rupture, and 
Fig. 25 Limits of the application of the method. 3D plot of the theoretical difference between relative time durations measured from directive and antidirective directions versus observation distance and rupture length for unilateral ruptures. As an example, the values of $\Delta \tilde{T}_{0}$ are shown for five real earthquakes

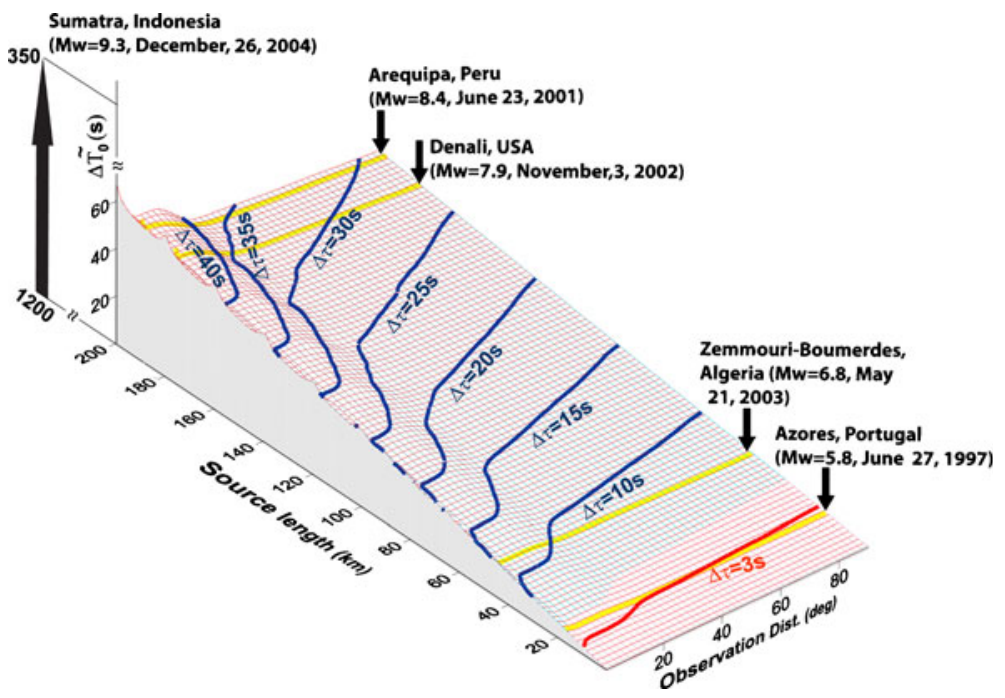

laterality of the rupture. We conclude that, in unilateral scenarios, the errors associated with the rupture direction and rupture velocity depend on the angular coverage of the stations (comparing scenarios $\mathrm{C} 1$ and $\mathrm{C} 3$ ). The error associated with the rupture direction is, in general, of the same order of magnitude as the maximum azimuthal gap. The methodology is insensitive to changes to the focal mechanism (comparison of scenarios S1, S2, and S3). Low rupture velocity produces directivity marks, which are less obvious on seismograms but are still identifiable. However, the parameters estimated present a larger disparity (comparing scenarios C3 and C4). The results from the bilateral section of scenario $\mathrm{C} 2$ show an evident mismatch between the dataset and the theoretical model that could explain the high level of error found. We suggest interpreting these kinds of results as a bilaterality indicator. The results of complex scenarios ( $\mathrm{C} 1, \mathrm{C} 3$, and $\mathrm{C} 4)$ show that, systematically, the estimates of the first section of rupture have lower error rates than subsequent sections. We believe this is due to the increased interference along the seismic record.

The results obtained from the dataset of the four earthquakes analyzed agreed, in general, with the values presented by other authors using different methods and data (Table 7). The analysis of the rupture direction that this methodology allows us to estimate is one of the few simple options available to certify, between the two planes of focal mechanism, which corresponds to the rupture. Some of the observations made from the synthetic data are confirmed by real data. We found a bilateral rupture in section D1 of the November 3, 2002, Denali, AK, USA $\left(M_{\mathrm{w}}=7.8\right)$ earthquake from a dataset that does not produce a good fit with the theoretical model through a similar analysis used in the synthetic $\mathrm{C} 2$ scenario. For the four earthquakes studied, it was possible to detect changes both in the direction of the rupture and in its speed.

One of the most sensitive parts of this study is the accurate determination of the time of arrival of common pulses. To avoid this problem, we are developing a method based on the "analysis in the frequency along the time domain".

Acknowledgements The authors wish to express their gratitude for the valuable discussion provided by Prof. E. Buforn (Universidad Complutense de Madrid) and acknowledge helpful reviews of two anonymous reviewers. This work has been developed with the support of the Fundação para a Ciência e Tecnologia, through project PTDC/CTE-GIN/82704/2006: "SISMOD/LISMOTFinite Seismic Source Modeling by Joint Inversion of Seismic and Geodesic Data and Strong ground motion in the Lower Tagus Valey" and Centro de Geofísica de Évora (Portugal)_CGE/SEISMOLITOS.

Open Access This article is distributed under the terms of the Creative Commons Attribution Noncommercial License which permits any noncommercial use, distribution, and reproduction in any medium, provided the original author(s) and source are credited. 
Appendix

Table 8 Common time delays measured on the seismograms in Figs. 6, 7, and 8 used for the synthetic tests (Figs. 10, 11, and 12)

\begin{tabular}{|c|c|c|c|c|c|c|c|c|c|c|c|c|}
\hline \multicolumn{2}{|c|}{ Observation points } & \multicolumn{11}{|c|}{ Time intervals reads in synthetic seismograms of each scenario (s) } \\
\hline \multirow[t]{2}{*}{$\overline{\#}$} & \multirow[t]{2}{*}{$\phi(\mathrm{deg})$} & \multirow[t]{2}{*}{$\overline{S 1}$} & \multirow[t]{2}{*}{ S2 } & \multirow[t]{2}{*}{ S3 } & \multirow[t]{2}{*}{ S4 } & \multirow[t]{2}{*}{ S5 } & \multicolumn{2}{|c|}{ S6 } & \multicolumn{2}{|c|}{$\mathrm{C} 1$} & \multicolumn{2}{|l|}{$\mathrm{C} 2$} \\
\hline & & & & & & & $\mathrm{I}$ & II & Part I & Part II & Part I & Part II \\
\hline 1 & 0 & 8.1 & 6.9 & 7.0 & 8.3 & 7.7 & 7.7 & 9.8 & 48.8 & 43.3 & 15.8 & 21.6 \\
\hline 2 & 15 & 7.5 & 6.9 & 7.1 & 7.7 & 7.7 & 7.1 & 10.2 & 46.6 & 41.8 & 16.4 & 23.4 \\
\hline 3 & 30 & 7.3 & 7.1 & 7.1 & 7.7 & 7.6 & 6.6 & 10.5 & 44.0 & 39.9 & 16.6 & 25.2 \\
\hline 4 & 45 & 7.0 & 7.2 & 7.3 & 7.7 & 7.5 & 6.3 & 10.8 & 42.1 & 37.1 & 16.8 & 26.7 \\
\hline 5 & 60 & 6.9 & 7.6 & 7.8 & 7.2 & 7.4 & 6.0 & 11.0 & 39.6 & 35.3 & 17.9 & 27.5 \\
\hline 6 & 75 & 6.9 & 8.1 & 8.0 & 7.4 & 7.7 & 6.0 & 11.0 & 37.3 & 33.2 & 17.7 & 29.2 \\
\hline 7 & 90 & 7.0 & 8.6 & 8.4 & 7.7 & 8.0 & 6.3 & 10.8 & 35.7 & 31.9 & 17.7 & 30.6 \\
\hline 8 & 105 & 7.3 & 9.3 & 8.8 & 8.0 & 7.9 & 6.7 & 10.6 & 34.4 & 31.2 & 17.7 & 31.6 \\
\hline 9 & 120 & 7.6 & 9.7 & 9.6 & 7.9 & 8.7 & 7.1 & 10.2 & 33.6 & 30.6 & 17.9 & 31.9 \\
\hline 10 & 135 & 7.9 & 10.2 & 10.3 & 8.6 & 8.8 & 7.7 & 9.8 & 33.1 & 30.9 & 17.8 & 31.9 \\
\hline 11 & 150 & 8.7 & 10.5 & 10.6 & 8.7 & 9.3 & 8.5 & 9.2 & 33.6 & 30.6 & 17.7 & 31.9 \\
\hline 12 & 165 & 9.2 & 10.7 & 10.8 & 9.3 & 9.6 & 9.2 & 8.6 & 34.7 & 32.1 & 17.7 & 30.9 \\
\hline 13 & 180 & 9.7 & 10.8 & 10.9 & 9.8 & 9.8 & 9.8 & 7.7 & 36.5 & 32.3 & 17.5 & 30.2 \\
\hline 14 & 195 & 10.1 & 10.8 & 10.8 & 9.9 & 10.0 & 10.2 & 7.0 & 38.4 & 34.8 & 17.2 & 29.1 \\
\hline 15 & 210 & 10.5 & 10.7 & 10.8 & 10.1 & 10.2 & 10.4 & 6.5 & 40.6 & 36.3 & 17.3 & 27.7 \\
\hline 16 & 225 & 10.6 & 10.5 & 10.6 & 10.5 & 10.4 & 10.5 & 6.4 & 42.9 & 38.4 & 17.0 & 25.6 \\
\hline 17 & 240 & 10.7 & 10.1 & 10.2 & 10.9 & 10.0 & 10.6 & 6.3 & 45.3 & 40.7 & 16.4 & 24.7 \\
\hline 18 & 255 & 10.7 & 9.9 & 9.6 & 10.3 & 10.0 & 10.6 & 6.3 & 47.5 & 42.2 & 16.6 & 22.7 \\
\hline 19 & 270 & 10.6 & 9.4 & 8.9 & 10.3 & 9.9 & 10.5 & 6.4 & 49.5 & 43.5 & 16.7 & 20.9 \\
\hline 20 & 285 & 10.5 & 8.7 & 8.5 & 10.2 & 9.4 & 10.4 & 6.5 & 50.9 & 44.5 & 16.4 & 20.5 \\
\hline 21 & 300 & 10.0 & 8.0 & 8.2 & 9.9 & 9.1 & 10.2 & 7.0 & 51.7 & 45.1 & 16.4 & 19.9 \\
\hline 22 & 315 & 9.7 & 7.6 & 7.8 & 9.6 & 8.9 & 9.8 & 7.7 & 51.8 & 45.3 & 16.3 & 19.9 \\
\hline 23 & 330 & 9.3 & 7.3 & 7.4 & 9.3 & 8.6 & 9.2 & 8.6 & 51.1 & 45.1 & 15.8 & 20.3 \\
\hline 24 & 345 & 8.7 & 7.0 & 7.2 & 8.9 & 7.9 & 8.4 & 9.2 & 50.2 & 44.3 & 15.5 & 21.3 \\
\hline
\end{tabular}

Table 9 Common time delays measured on the seismograms of Fig. 9 and used for the synthetic seismograms shown in Fig. 13

\begin{tabular}{|c|c|c|c|c|c|c|}
\hline \multicolumn{3}{|c|}{ Observation points } & \multicolumn{4}{|c|}{$\begin{array}{l}\text { Time intervals reads in synthetic } \\
\text { seismograms of each scenario (s) }\end{array}$} \\
\hline \multirow[t]{2}{*}{ Name } & \multirow{2}{*}{$\begin{array}{l}\text { Azimuth } \\
\text { (deg) }\end{array}$} & \multirow[t]{2}{*}{$\Delta(\operatorname{deg})$} & \multicolumn{2}{|l|}{$\mathrm{C} 3$} & \multicolumn{2}{|l|}{$\mathrm{C} 4$} \\
\hline & & & Part I & Part II & Part I & Part II \\
\hline HRV & 1.5 & 58.7 & 58.5 & 27.1 & 47.4 & 56.7 \\
\hline SDV & 6.2 & 25.2 & 59.1 & 27.5 & 48.1 & 57.8 \\
\hline DRLN & 11.2 & 66.9 & 56.7 & 27.1 & 46.8 & 56.9 \\
\hline FDF & 16.8 & 32.2 & 57.2 & 26.6 & 47.4 & 57.5 \\
\hline DSB & 33.4 & 89.9 & 53.6 & 26.2 & 46.0 & 55.3 \\
\hline CMLA & 38.5 & 70.1 & 53.1 & 25.6 & 45.8 & 55.1 \\
\hline PAB & 46.3 & 84.9 & 52.3 & 25.0 & 45.4 & 55.2 \\
\hline SACV & 60.2 & 58.1 & 49.9 & 23.8 & 44.8 & 54.5 \\
\hline DBIC & 77.0 & 71.5 & 48.9 & 22.6 & 44.6 & 53.6 \\
\hline RCBR & 78.6 & 38.1 & 46.6 & 22.0 & 43.9 & 52.8 \\
\hline $\mathrm{ASCN}$ & 89.4 & 58.1 & 46.4 & 22.1 & 44.3 & 52.8 \\
\hline TSUM & 108.7 & 85.6 & 47.8 & 21.9 & 43.9 & 53.3 \\
\hline SUR & 122.2 & 84.8 & 47.4 & 21.9 & 43.9 & 52.4 \\
\hline
\end{tabular}


Table 9 (continued)

\begin{tabular}{|c|c|c|c|c|c|c|}
\hline \multicolumn{3}{|c|}{ Observation points } & \multicolumn{4}{|c|}{$\begin{array}{l}\text { Time intervals reads in synthetic } \\
\text { seismograms of each scenario (s) }\end{array}$} \\
\hline \multirow[t]{2}{*}{ Name } & \multirow{2}{*}{$\begin{array}{l}\text { Azimuth } \\
\text { (deg) }\end{array}$} & \multirow[t]{2}{*}{$\Delta(\operatorname{deg})$} & \multicolumn{2}{|l|}{$\mathrm{C} 3$} & \multicolumn{2}{|l|}{$\mathrm{C} 4$} \\
\hline & & & Part I & Part II & Part I & Part II \\
\hline HOPE & 151.7 & 47.6 & 44.7 & 21.2 & 43.1 & 49.9 \\
\hline NIEB & 169.8 & 20.3 & 45.6 & 21.3 & 42.5 & 49.1 \\
\hline SPA & 180.0 & 73.9 & 50.5 & 23.6 & 43.8 & 51.3 \\
\hline SBA & 190.7 & 80.2 & 52.0 & 24.1 & 44.4 & 51.5 \\
\hline RAR & 250.4 & 81.0 & 59.0 & 25.4 & 46.3 & 57.0 \\
\hline POHA & 291.1 & 88.4 & 60.9 & 27.3 & 46.9 & 57.9 \\
\hline PAS & 320.3 & 66.0 & 62.1 & 28.2 & 47.4 & 57.8 \\
\hline WUAZ & 325.7 & 63.0 & 62.1 & 28.6 & 47.4 & 57.5 \\
\hline NEW & 331.5 & 75.3 & 60.9 & 28.3 & 47.4 & 57.4 \\
\hline HKT & 334.7 & 51.0 & 62.1 & 29.3 & 47.3 & 59.5 \\
\hline $\mathrm{CCM}$ & 343.1 & 56.8 & 60.9 & 27.6 & 47.4 & 58.2 \\
\hline
\end{tabular}

\section{References}

Ammon CJ, Chen J, Hong-Kie T, Robinson D, Ni S, Hjorleifsdottir V, Kanamori H, Lay T, Das S, Helmberger D, Ichinose G, Polet J, Wald D (2005) Rupture process of the 2004 Sumatra-Andaman earthquake. Science 308:1133-1139. doi:10.1126/ science. 1112260

Aki K, Richards PG (1980) Quantitative seismology: theory and methods, vol 2. Freeman and Co., San Francisco

Ayadi A, et al (2003) Strong Algerian earthquake strikes near capital city. Eos Trans AGU 84(50):561-568. doi:10.1029/2003EO500002

Ayadi A, Dorbath C, Ousadou F, Maouche S, Chikh M, Bounif MA, Meghraoui M (2008) Zemmouri earthquake rupture zone (Mw 6.8, Algeria): aftershocks sequence relocation and 3-D velocity model. J Geophys Res 113:B09301. doi:10.1029/2007JB005257

Baumont D, Courboulex F, Scotti O, Melis NS, Stavrakakis G (2002) Slip distribution of the Mw 5.9, 1999 Athens earthquake inverted from regional seismological data. Geophys Res Lett 29(1720):15.1-15.4. doi:10.1029/2001GL014261

Beck S, Silver P, Wallace T, James D (1995) Directivity analysis of the deep Bolivian earthquake of June 9, 1994. Geophys Res Lett 22:2257-2260

Belabbès S, Wicks CZ, Akir C, Meghraoui M (2009) Rupture parameters of the 2003 Zemmouri (Mw 6.8), Algeria, earthquake from joint inversion of interferometric synthetic aperture radar, coastal uplift, and GPS. J Geophys Res 114:B03406. doi:10.1029/ 2008JB005912

Benioff $H$ (1955) Mechanism and strain characteristics of the white wolf fault as indicated by the aftershock sequence. Calif Div Mines Bull 171:199-202

Ben-Menahem A (1961) Radiation of seismic surfacewaves from finite moving sources. Bull Seismol Soc Am 51:401-435
Ben-Menahem A, Singh SJ (1981) Seismic waves and sources. Springer, New York

Beresnev IA (2003) Uncertainties in finite-fault slip inversions: to what extend to believe? (A critical review). Bull Seismol Soc Am 93:2445-2458

Bezzeghoud M, Buforn E (1999) Source parameters of 1992 Melilla (Spain, Mw = 4.8), 1994 Alhoceima (Morocco, Mw = 5.8) and 1994 Mascara (Algeria, $\mathrm{Mw}=5.7)$ earthquakes and seismotectonic implications. Bull Seismol Soc Am 89(2):359-372

Bilham R, Engdahl ER, Feldl N, Satyabala SP (2005) Partial and complete rupture of the Indo-Andaman plate boundary 1847-2004. Seismol Res Lett 76(3):299-311. doi:10.1785/gssrl.76.3.299

Bilek S, Ruff L (2002) Analysis of the 23 June 2001 $\mathrm{Mw}=9.4$ Peru underthrusting earthquake and its aftershocks. Geophys Res Lett 29(20):21.1-21.4. doi:10.1029/2002GL015543

Boore D, Joyner W (1978) The influence of rupture incoherence on seismic directivity. Bull Seismol Soc Am 68:283-300

Borges J (2003) Fonte Sísmica Em Portugal-Algumas Implicações Na Geodinâmica Da Região AçoresGibraltar. PhD thesis, Évora University

Bouchon M, Toksöz N, Karabulut H, Bouin M, Dietrich M, Aktar M, Edie M (2002) Space and time evolution of rupture and faulting during the 1999 Izmit (Turkey) earthquake. Bull Seismol Soc Am 92:256-266

Buforn E, Bezzeghoud M, Udias A, Pro C (2004) Seismic source in the Iberian-African plate boundary. Pageoph 161(3):623-646

Bullen KE, Bolt B (1985) Introduction to the theory of seismology. Cambridge University Press, Cambridge

Caldeira B (2004) Caracterização espaço-temporal da fonte sísmica-Processos de rupture e directividade. $\mathrm{PhD}$ thesis, Évora University

Caldeira B, Bezzeghoud M, Borges J (2004) Contributo da directividade para a caracterização da Fonte do sismo de Boumerdes (Argélia) de 21 de Maio de 2003, Mw = 
6.7. 4 Assembleia Luso-Espanhola de Geodesia e Geofísica, pp 251-252

Cipar J (1979) Source processes of the Haicheng, China earthquake from observations of $\mathrm{P}$ and $\mathrm{S}$ waves. Bull Seismol Soc Am 69:1903-1916

Das S, Kostrov BV (1990) Inversion for seismic slip rate history and distribution with stabilizing constraints application to the 1986 Andrean of islands earthquake. J Geophys Res 95(B5):6899-6913

Day S (1982) Three dimensional simulation of spontaneous rupture: the effect of nonuniform pre-stress. Bull Seismol Soc Am 72:1881-1901

Delouis B, Vallée M, Meghraoui M, Calais E, Mahsas S, Briole P, Benhamouda F, Yelles K (2004) Slip distribution of the 2003 Boumerdes-Zemmouri earthquake, Algeria, from teleseismic, GPS, and coastal uplift data. Geophys Res Lett 31:L18607. doi:10.1029/ 2004GL020687

Douglas A, Hudson J, Pearce R (1988) Directivity and the Doppler effect. Bull Seismol Soc Am 78:1367-1372

Dunham M, Archuleta RJ (2004) Evidence for a supershear transient during the 2002 Denali fault earthquake. Bull Seismol Soc Am 94:S256-S268

Eberhart-Phillips D, Haeussler P et al (2003) The 2002 Denali fault earthquake, Alaska: a large magnitude, slip-partitioned event. Science 300:1113-1118. doi:10. 1126/science. 1082703

Frankel A (2004) Rupture process of the M 7.9 Denali fault, Alaska, earthquake: subevents, directivity, and scaling of high-frequency ground motions. Bull Seismol Soc Am 94:S234-S255

French AP (1974) Vibrations and waves. Norton, New York

Fukao Y (1972) Source process of a large deep-focus earthquake and its tectonic implications-the western Brazil earthquake of 1963. Phys Earth Planet Inter 5:61-76

Grach SM, Komrakov GP, Yurishchev MA, Thid B, Leyser TB, Carozzi T (1997) Multifrequency Doppler radar observations of electron gyroharmonic effects during electromagnetic pumping of the ionosphere. Phys Rev Lett 78(5):883-886. doi:10.1103/PhysRevLett78.883

Haskell NA (1964) Total energy and energy spectral density of elastic wave radiation from propagating faults. Bull Seismol Soc Am 54:1811-1841

Hoshiba M (2003) Fluctuation of wave amplitude even when assuming convolution of source, path and site factors-effect of rupture directivity. Phys Earth Planet Inter 137:45-65

Ihmlé PF (1998) On the interpretation of subevents in teleseismic waveforms: the 1994 Bolivia deep earthquake revisited. J Geophys Res 103(B8):17,919-17,932

Ishii M, Shearer P, Houston H, Vidale J (2005) Extend, duration and speed of the 2004 Sumatra-Andaman earthquake imaged by the Hi-Net array. Nature 435: 933-936. doi:10.1038/nature03675

Kasahara K (1981) Earthquakes mechanics. Cambridge Univ. Press, Cambridge

Kennett B, Engdahl E (1991) Traveltimes for global earthquake location and phase identification. Geophys J Int 105:429-465
Kikuchi M, Kanamori H (1991) Inversion of complex body waves-III. Bull Seismol Soc Am 81:23352350

Kikuchi M, Yamanaka Y (2002) Source rupture processes of the central Alaska earthquake of Nov. 3, 2002, inferred from teleseismic body waves, EIC Seismological Note. No. 129 , Nov. 4

Kraeva N (2004) Tikhonov's regularization for deconvolution in the empirical green function method and vertical directivity effect. Tectonophysics 383:29-44

Krüger F, Ohrnberger M (2005a) Tracking the rupture of the $\mathrm{Mw}=9.3$ Sumatra earthquake over $1,150 \mathrm{~km}$ at teleseismic distance. Nature 435:937-939. doi:10.1038/nature03696

Krüger F, Ohrnberger M (2005b) Spatio-temporal source characteristics of the 26 December 2004 Sumatra earthquake as imaged by teleseismic broadband arrays. Geophys Res Lett 32:L24312. doi:10.1029/ 2005GL023939

Lambotte S, Rivera L, Hinderer J (2007) Constraining the overall kinematics of the 2004 Sumatra and the 2005 Nias earthquakes using the earth's gravest free oscillations. Bull Seismol Soc Am 97(1A):S128-S138. doi:10.1785/0120050621

Lay T, Kanamori H, Ammon C, Nettles M, Wald SN, Aster RC, Beck S, Bilek S, Brudzinski MR, Butler R, DeShon HR, Ekstrom G, Satake K, Sipkin S (2005) The great Sumatra-Andaman earthquake of 26 December 2004. Science 308(5725):1127-1133. doi: 10.1126/science. 1112250

Le Pichon A, Guilbert J, Vega A, Garce's M, Brachet N (2002) Ground-coupled air waves and diffracted infrasound from the Arequipa earthquake of June 23, 2001. Geophys Res Lett 29(18):33.1-33.4. doi:10.1029/ 2002GL015052

Liao BY, Huang H (2008) Rupture process of the $2002 \mathrm{Mw}$ 7:9 Denali earthquake, Alaska, using a newly devised hybrid blind deconvolution method. Bull Seismol Soc Am 98:162-179. doi:10.1785/0120050065

Loupas T, Gill RW (1994) Multifrequency Doppler: improving the quality of spectral estimation by making full use of the information present in scattered RF echoes. Ultrason Ferroelectr Freq Control 41(4):522531. doi:10.1109/58.294114

Menke W (1984) Geophysical data analysis: discrete inverse theory. Academic, Orlando

Ni S, Hiro K, Don H (2005) Seismology: energy radiation from the Sumatra earthquake. Nature 434:582. doi:10.1038/434582a

Ozacar AA, Beck SL (2004) The 2002 Denali fault and 2001 Kunlun fault earthquakes: complex rupture processes of two large strike-slip events. Bull Seismol Soc Am 94(6B):S278-292. doi:10.1785/0120040604

Pritchard M, Norabuena E, Ji C, Boroschek R, Comte D, Simons M, Dixon TH, Rosen PA (2007) Geodetic, teleseismic, and strong motion constraints on slip from recent southern Peru subduction zone earthquakes. J Geophys Res 112:B03307. doi:10.1029/2006JB004294

Pro MC (2002) Estudio del efecto de directividad en la forma de ondas. PhD thesis, Universidad Compultense de Madrid 
Pro C, Buforn E, Udías A (2007) Rupture length and velocity for earthquakes in the Mid-Atlantic Ridge from directivity effect in body and surface waves. Tectonophysics V 433:65-79

Rao IS, Anandan VQ, Kumar MS (2009) Multifrequency decoding of a phased array Doppler sodar. J Atmos Ocean Technol 26(4):759-768

Rhie J, Dreger D, Bürgmann R, Romanowicz B (2007) Slip of the 2004 Sumatra-Andaman earthquake from joint inversion of long period global seismic waveforms and GPS static offsets. Bull Seismol Soc Am 97(1A): S115-S127

Russell D, Brucher R (2002) Multifrequency Doppler discriminates between baseous and solid microemboli. Ann Thorac Surg 73(1):S369

Robinson DP, Das S, Watts AB (2006) Earthquake rupture stalled by a subducting fracture zone. Science 312:1203-1205

Semmane F, Campillo M, Cotton F (2005) Fault location and source process of the Boumerdes, Algeria, earthquake inferred from geodetic and strong motion data. Geophys Res Lett 32:L01305. doi:10.1029/ 2004GL021268

Sekiguchi H, Iwata T (2002) Rupture process of the 1999 Kocaeli, Turkey, earthquake estimated from strong-motion waveforms. Bull Seismol Soc Am 92: 300-311

Tavera H, Buforn E, Bernal I, Antayhua Y, Vilacapoma L (2002) The Arequipa (Peru) earthquake of June 23, 2001. J Seismol 6(2):279-283
Tibi R, Estabrook C, Bock G (1999) The 1996 June 17 Flores sea and 1994 March 9 Fiji-Tonga earthquakes: source processes and deep earthquake mechanisms. Geophys J Int 138:625-642

Tregoning P, Brunner FK, Bock YS, Puntodewo SO, McCaffrey R, Genrich JF, Calais E, Rais J, Subarya C (1994) First geodetic measurement of convergence across the Java Trench. Geophys Res Lett 21:21352139

Tumarkin A, Archuleta R (1994) Empirical ground motion prediction. Ann Geofis XXXVII:1691-1720

Udias A (1971) Source parameters of earthquakes from spectra of Rayleigh waves. Geophys J R Astron Soc 22:253-276

Vallée M (2007) Rupture properties of the giant Sumatra earthquake imaged by empirical green function analysis. Bull Seismol Soc Am 97(1A):S103-S114

Velasco A, Ammon CJ, Farrell J, Pankow K (2004) Rupture directivity of the 3 November 2002 Denali fault earthquake determined from surface waves. Bull Seismol Soc Am 94(6B):S293-S299. doi:10.1785/ 0120040624

Vigny C, Simons W, Abu S, Bamphenyu R, Satirapod C, Choosakul N, Subarya C, Socquet A, Omar K, Abidin HZ, Ambrosius BA (2005) Insight into the 2004 Sumatra-Andaman earthquake from GPS measurements in southeast Asia. Nature 436:201-206

Yagi Y (2003) Source process of large and significant earthquakes in 2003. Bull Int Inst Seismol Earthq Eng v.37:145-153. http://iisee.kenken.go.jp/staff/yagi/pdf/ YagiBIISEE.pdf 